Article

\title{
Laundry Care Regimes: Do the Practices of Keeping Clothes Clean Have Different Environmental Impacts Based on the Fibre Content?
}

\author{
Kirsi Laitala ${ }^{1}$ **D , Ingun Grimstad Klepp ${ }^{1}$, Roy Kettlewell ${ }^{2}$ and Stephen Wiedemann ${ }^{3}$ \\ 1 Consumption Research Norway (SIFO), Oslo Metropolitan University, 0130 Oslo, Norway; \\ ingunk@oslomet.no \\ 2 Kettlewell Consulting, Unit 2, 33 Clovelly Road, Hornsby, Sydney 2077, Australia; \\ roy@kettlewellconsulting.com.au \\ 3 Integrity Ag \& Environment, 10511 New England Highway, Highfields 4352, Australia; \\ Stephen.Wiedemann@integrityag.net.au \\ * Correspondence: kirsil@oslomet.no; Tel.: +47-672-356-32
}

Received: 11 August 2020; Accepted: 10 September 2020; Published: 12 September 2020

\begin{abstract}
Clothing maintenance is necessary for keeping clothing and textiles functional and socially acceptable, but it has environmental consequences due to the use of energy, water and chemicals. This article discusses whether clothes made of different materials are cleaned in different ways and have different environmental impacts. It fills a knowledge gap needed in environmental assessments that evaluate the impacts based on the function of a garment by giving detailed information on the use phase. The article is based on a quantitative wardrobe survey and qualitative laundry diary data from China, Germany, Japan, the UK and the USA. The largest potential for environmental improvement exists in reducing laundering frequency and in the selection of washing and drying processes, and through a transition to fibres that are washed less frequently, such as wool. Adopting best practice garment care would give larger benefits in countries like the US where the consumption values were the highest, mainly due to extensive use of clothes dryers and less efficient washing machines combined with frequent cleaning. These variations should be considered in environmental assessments of clothing and when forming sustainability policies. The results indicate the benefits of focusing future environmental work on consumer habits and culture and not only technologies.
\end{abstract}

Keywords: laundry; clothing; energy use; water use; maintenance; dry clean; clothes dryers; fibre content; wardrobe audit; laundry diary

\section{Introduction}

Textiles surround us in our everyday lives in the form of clothes, bed linen, carpets, curtains and other household textiles we use to warm, protect, dry, clean and decorate ourselves and our homes. Clothing maintenance is necessary for keeping clothing and textiles functional and socially acceptable [1,2]. The textile industry has been identified as one of the most important environmental polluters due to high resource use in production and during use [3-5]. Life cycle assessments (LCA) of clothing have indicated that length of the use phase, as well as maintenance, are decisive for impact assessment [6], and in many cases, the use phase has the highest environmental impacts for many key indicators [7-10]. It is estimated that consumers' use of domestic washing machines globally contribute to the use of about 20 trillion litres of water and $100 \mathrm{TWh}$ of electricity [11]. Clothing care has environmental consequences, including water pollution, eutrophication, greenhouse gas emissions and potential toxicity impacts [12]. For example, electricity use alone equates to $47.5 \mathrm{MtCO}_{2} \mathrm{e}$ emissions [13]. These figures exclude other laundry care activities such as professional and industrial 
laundering, washing by hand, use of clothes dryers, ironing, dry cleaning, and use of laundromats or shared laundry facilities. The Carbon Trust has estimated that the use phase of clothing is a major climate gas contributor with $530 \mathrm{MtCO}_{2 \mathrm{e}}$ emissions per year through laundering, drying, ironing and dry cleaning [14], which equates roughly to the annual $\mathrm{CO}_{2}$ emissions from 136 coal-fired power plants [15].

Laundering also contributes to pollution of waterways such as the spread of harmful chemicals from detergents, solvents and softeners [16-20] as well as microfibres and textile chemicals [21-23]. These impacts vary globally depending on water scarcity, and infrastructure such as wastewater treatment plants.

The environmental impact of energy use in laundering varies between countries based on the forms of energy used [24,25]. However, all energy sources have some impact on the environment. Use of fossil fuels such as coal, oil, and natural gas are substantially more harmful than renewable energy sources for air and water pollution, damage to public health, wildlife and habitat loss, water use, land use, and global warming emissions [26]. However, even renewable energy sources such as wind, solar, geothermal, biomass, and hydropower have an impact, so reducing all forms of energy is beneficial. Consumers can reduce environmental impact through the choice of materials, design, washing frequencies, and cleaning methods $[27,28]$.

Bain et al. [12] have analysed methods of clothes cleaning in the UK, and suggested ways of saving energy and reducing $\mathrm{CO}_{2}$ emissions, including laundering at $30^{\circ} \mathrm{C}$ instead of $40{ }^{\circ} \mathrm{C}$, line drying instead of using clothes dryers, increasing spin-drying efficiency for more efficient water extraction and subsequent reduction in tumble drying, and finally, selecting washing appliances with a higher energy rating class.

Cleaning technologies vary worldwide from hand washing to various types of washing machines and dry cleaners [11,16,29-31]. In Europe, front-loading horizontal-axis drum washing machines dominate, while top-loaders and other washing technologies such as twin-tubs are more common in other continents [11,29]. New dry cleaning methods have been developed to reduce and replace the use of harmful chemicals such as perchloroethylene [32,33].

The amount of energy required for drying laundry varies between methods. Line drying outdoors requires no additional energy, while drying indoors in a heated room or at a laundry dryer consumes energy [34]. The energy use for clothes dryers often exceeds that of washing machines [35].

Legislation and regulations influence the efficiencies and environmental impact of cleaning technologies such as washing machines, dryers and detergents. These include eco-design requirements [36], Energy labelling framework [37,38], European Union regulation for Registration, Evaluation, Authorisation and Restriction of Chemicals (REACH) [39] and The Toxic Substances Control Act (TSCA) in the US [40], and eco-labelling scheme criteria [41].

This brief review identified global variation in environmental impacts of laundering depending on technologies, regulations and infrastructure. Variation is increased by climate and consumer practices, with cultural and social norms influencing when and why laundering is done [42-44]. For example, the focus has evolved from removing soil derived from the external environment towards concern about sweat and body odour from the internal environment [45].

Variation also arises from the type of textiles and clothing, and how we use them [46,47]. In general, outer layer garments are worn longer between washing than next-to-skin items [48] and the cleanliness of clothing worn in social situations is given higher priority than items only worn at home. Material properties affect how easily garments get dirty or odorous and how difficult they are to clean [45,49], while activity level and climate influence how much we sweat. Odour studies have shown the significant impact of fibre type on adsorption and release of volatile organic compounds due to the inherent chemical and physical structure differences between fibres. Wool shows the least intense odour followed by cotton, while synthetic materials polyester and polyamide show the most intense odour $[49,50]$. Unsurprisingly, odour in clothing impacts laundering practices, with odorous items are more likely to be washed in hot water than non-odorous items and synthetic athletic wear typically 
washed after each wear [48]. Airing is an effective way to remove the odour of sweat from woollens but less so in synthetics [45]. Laundering is more effective at removing odorants from cotton than from polyester [51]. Especially oleophilic polyester fibres are likely to build-up odour over time, while cellulosic fibres are more likely to exhibit unpleasant odours resulting from bacterial action under wet conditions [50]. However, cellulose materials dried outdoors in sunlight develop a distinctive but very pleasant smell [52].

Laundering has been researched widely related to the importance of cleanliness, housework and division of labour [53-55], as well as environmental impact [11,21,56-63]. Most environmental studies assess a specific geographic area, and thus do not identify and distinguish culture-specific effects from more general effects. Notwithstanding the important influence of fibre type, relatively little consideration is given to this variable's influence on the environmental impact of laundering.

A large knowledge gap exists in understanding how these significant variations in the maintenance of different materials, garment types and geographic areas influence the magnitude of environmental impacts from clothing use. Our research aims to address this knowledge gap. This is especially important for cradle-to-grave LCAs that assess impacts based on the function of a garment. According to European Commission guidance, the system's function and functional unit are central elements of an LCA, and without them, a meaningful and valid comparison of products is not possible [64]. With use intensity playing a dominant role, the availability of quantified information on the use phase becomes crucial [64]. This will become even more significant if the current EU legislative proposal on substantiating green claims related to the environmental performance of products and businesses will become effective [65]. The regulation will require companies to substantiate claims they make about the environmental footprint by using standardised methods such as Product Environmental Footprint Category Rules (PEFCRs) for quantifying them. The current methodology for $\mathrm{t}$-shirts uses functional unit "To wear a clean T-shirt until it becomes dirty 52 times" [66], where 52 is the assumed number of washes tolerated by the T-shirt. Van der Velden et al. [67] point out that there is a to lack of empirical consumer studies on garment wearing and laundry behaviours, which should include information of the type of cleaning cycle and temperature as well as drying.

This article discusses whether the practices of cleaning clothes made of different fibres have different environmental impacts. We will compare laundering frequency and cleaning methods of similar garments made of different materials based on a wardrobe survey and laundry diaries collected in China, Germany, Japan, United Kingdom and the United States and offer suggestions for reducing the environmental impacts of laundering, measured as electricity and water use.

The remaining part of the paper proceeds as follows: We will introduce the methodology for this study and describe the methods. The following section presents the results and discussion, focusing on the three key themes: (1) laundering methods, (2) frequencies and (3) the related environmental impacts of selected garment categories. The final section gives conclusions, implications and recommendations.

\section{Materials and Methods}

This article is based on two types of international data presented below: a wardrobe survey and qualitative laundry diary data. Data on energy and water use are sourced from the literature.

All analyses have been carried out using IBM SPSS statistics version 25 software.

\subsection{Wardrobe Survey}

The wardrobe survey was conducted by AC Nielsen at the end of 2018 in five countries with large clothing markets: USA, China, Japan, the UK and Germany. Over two hundred consumers from each country answered a comprehensive web-based survey on their wardrobe contents. Wardrobe audit as a method has been previously described by Fletcher and Klepp [68] and Klepp and Bjerck [69].

Questions included the number of owned items in specified categories, and for a selection of these items, details such as clothing lifespan, active use time, wear occasions, materials and laundering 
practices were registered [70]. This enables us to compare the use of similar clothing items in different parts of the world.

The survey focused on adult respondents between 18 to 64 years old with equal gender distribution. The sample was pre-stratified to represent the demographics of the country in question and weighted subsequently to population. The respondent demographics for each country are given in Table 1 . For enabling different analysis, one database was prepared per respondent $(\mathrm{N}=1111)$, and another per garment $(N=53,461)$. China differs from the other countries, as the sample was selected to represent the ten largest cities only and is therefore not representative for the whole country. This enables comparison of more similar consumer groups in terms of living standard in the five countries. In China, only about $5 \%$ of people over 55 years use the internet [71], and consequently, the oldest age group is underrepresented in the sample.

Table 1. Survey respondents' background demographics (weighted respondent data).

\begin{tabular}{lcccccc}
\hline & Total & China & Germany & Japan & UK & USA \\
\hline Number of respondents & $\mathrm{N}=1111$ & 230 & 224 & 224 & 213 & 220 \\
\hline $\begin{array}{l}\text { Gender distribution } \\
\text { Men }\end{array}$ & $50.5 \%$ & $54 \%$ & $51 \%$ & $51 \%$ & $47 \%$ & $49 \%$ \\
$\quad$ Women & $49.5 \%$ & $46 \%$ & $49 \%$ & $49 \%$ & $53 \%$ & $51 \%$ \\
\hline Age groups & & & & & & \\
18-29 years & $25 \%$ & $41 \%$ & $19 \%$ & $19 \%$ & $22 \%$ & $21 \%$ \\
30-49 years & $47 \%$ & $49 \%$ & $45 \%$ & $50 \%$ & $52 \%$ & $44 \%$ \\
50-64 years & $28 \%$ & $10 \%$ & $36 \%$ & $31 \%$ & $26 \%$ & $35 \%$ \\
\hline Garment data & & & & & & \\
$\quad$ Total number of registered garments & 53,461 & 10,595 & 11,705 & 12,022 & 9384 & 9755 \\
$\quad$ Formal wear (suits, trousers and skirts) & 6080 & 1495 & 897 & 1660 & 958 & 1070 \\
T-shirts/polo shirts/singlets/tanks & 9441 & 1326 & 2346 & 2083 & 1624 & 2062 \\
$\quad$ Pairs of socks/stockings & 9917 & 1814 & 2177 & 2024 & 1927 & 1975 \\
\hline
\end{tabular}

To keep the survey length manageable and prevent respondent wear-out, the number of clothing categories assessed in detail was limited to categories of common clothing items including pants and trousers, skirts and dresses (F), jumpers, sweaters and cardigans, T-shirts and polos, singlets and tanks $(\mathrm{F})$, thermal underwear, sportswear, jackets and blazers, coats, socks, stockings $(\mathrm{F})$, suits $(2 \mathrm{pc})$, and scarfs. This means that questions asked for specific clothing items were only answered for these types of clothing. Item-specific questions were also limited to a maximum of 10 items per category to combat respondent fatigue.

For fibre categories, we use the following groups and definitions:

- Wool and blends include pure wool, merino, cashmere and wool blend materials

- Cotton and blends include pure cotton, denim and cotton blend materials

- Synthetic fibres include all synthetic fibres. The most common types were given as examples in the questionnaire (polyester, polyamide/nylon, acrylic, and polypropylene)

- Regenerated cellulosic fibres include all fibres manufactured from cellulose. The most common types were given as examples in the questionnaire (viscose/rayon, modal, lyocell and acetate).

- When the term "man-made fibres" is used, the category refers both to synthetic and regenerated fibres.

\subsection{Laundry Diaries}

About 30 participants from each country answered an additional detailed qualitative study where they kept a diary of their laundry activities for four weeks (Table 2). During this period, the participants registered all cloth cleaning and drying occasions in an online diary, including the contents of their laundry. In addition, they were asked to take a picture of the washing machine, hand-washing 
equipment, dryer and detergents that were used. These data are structured by laundry activity (3253 events).

Table 2. Laundry diary study participants and activities.

\begin{tabular}{|c|c|c|c|c|c|c|}
\hline & China & Germany & Japan & UK & USA & Total \\
\hline Number of informants & 29 & 34 & 25 & 30 & 26 & 144 \\
\hline Number of registered laundry activities & 715 & 613 & 827 & 604 & 494 & 3253 \\
\hline Average number of registered activities per household & 24.7 & 18.0 & 33.1 & 20.1 & 19.0 & 22.6 \\
\hline \multicolumn{7}{|l|}{ Gender distribution } \\
\hline Men & $48 \%$ & $47 \%$ & $40 \%$ & $47 \%$ & $35 \%$ & $44 \%$ \\
\hline Women & $52 \%$ & $53 \%$ & $60 \%$ & $53 \%$ & $65 \%$ & $56 \%$ \\
\hline \multicolumn{7}{|l|}{ Age group } \\
\hline $18-29$ years & $28 \%$ & $6 \%$ & $12 \%$ & $10 \%$ & $8 \%$ & $13 \%$ \\
\hline $30-49$ years & $72 \%$ & $38 \%$ & $60 \%$ & $57 \%$ & $50 \%$ & $55 \%$ \\
\hline $50-64$ years & $0 \%$ & $56 \%$ & $28 \%$ & $33 \%$ & $42 \%$ & $33 \%$ \\
\hline Average household size in number of persons & 4.0 & 2.2 & 3.0 & 3.2 & 2.9 & 3.1 \\
\hline
\end{tabular}

\subsection{Energy and Water Use Data}

Energy and water use data for the washing machines and dryers used by diary informants were determined based on internet searches on the machine brand and model numbers. At the same time, the information registered by informants was verified, including the washing machine/dryer capacity and maximum spinning speed.

The availability of information varied greatly between countries. It was more easily determined in Europe, where most newer machines have energy labelling information available online including the yearly consumption values based on the cotton program. Some user manuals have even more detailed information available for the specific programmes and temperatures. We used this machine and program-specific information for the energy and water use for the UK and Germany, as well as for the different fibre types. Many Chinese machines had an energy label providing information about the energy and water use and usually also capacity.

In the US water use data are not given, and energy use data are available only for machines with Energy guide labelling. Therefore, we have chosen to use data provided by Energy Star. They give information about the average values of labelled machines, and how much they save compared to regular machines. In this evaluation, we assume that half of the machines are Energy Star labelled and half are not, and use average values for the two machine types. This equals to $1.21 \mathrm{kwh} / \mathrm{cycle}$ and 64.4 litres/cycle. Since the washing machine capacity in the US is usually given in volume (cubic feet) instead of weight of the laundry, we have used Energy Star's conversion chart to convert to maximum laundry filling weight [38]. The average value was given for a $3.5 \mathrm{cu} . \mathrm{ft}$. machine equates to about $6.6 \mathrm{~kg}$ capacity.

In Japan, there is no mandatory energy labelling scheme for washing machines. This could be due to the common practice of using unheated water for laundering. Therefore, we used cold water wash program of European front-loading machine for the estimation of consumption values in Japan.

Many top-loading machines in the US and Japan do not report spin-drying speed in rpm but use scales instead (for example 0 to 3 ), or sometimes mph (miles per hour). In China, the efficiency is given sometimes in watts to indicate dehydration power instead of giving the spinning speed.

There were also a lack of comprehensive data for clothes dryers. Since the main difference between dryer types is in their functionality of either being vented, condenser, air-pump condenser or washer-dryer combo, we have used these main categories to estimate the energy and water use per type, and then used the diary data to see how common the different types of machines are in each country. Tumble dryers use either gas or electricity. In our data, the overwhelming majority of dryers used electricity, so we used this in the calculations. 
Energy and water use data for dry cleaning and carbon emissions for the production of detergents were based on a literature review reported in Appendix A.

\section{Results}

In this section, we discuss general laundering practices and draw more specific examples of three garment groups: formal wear (suits, formal trousers and skirts), t-shirts/polo shirts/singlets, and socks and stockings. The two latter groups are frequently laundered while the first is cleaned less often, and it is more common to dry clean them. We will discuss the environmental impacts of different cleaning and drying methods.

\subsection{Cleaning and Drying Methods}

The cleaning methods are of great importance for environmental impact. They are dependent on access to technology and infrastructure, but also to knowledge, habits and culture. As we shall see, there are large variations between the countries.

Table 3 shows which laundry appliances and cleaning methods are available in the survey respondents' households. We have asked questions both related to ownership, and whether the appliances are in use. Most figures related to ownership and use are at a rather similar level, with only a few per cent points differences in lower use rates than ownership rates. China has the largest variation in washing machine types. Top-loading washing machines are most common in Japan and the US, while Europeans use mainly front-loaders, as previous research also has indicated [11]. Even though the survey shows that top-loading machines are also used in Europe, these are still most likely to have a drum with horizontal axis and function similar to front-loading machines (Table 4). Tumble dryers are most common in the US, while they are rarely used in Japan or China. Line drying indoors is slightly more common than outdoors in other countries besides Japan. Using shared appliances such as laundromat or machine in an apartment complex is most common in Japan and in the US. Washing laundry by hand is a common practice in China, where $96 \%$ of respondents said that they wash some of their laundry by hand. This is the second most common in Japan (65\%), while only bit over half of Germans, Brits and Americans say the same.

Table 3. Answer distribution to questions "Please indicate which of the following items you have currently in your household", "Please indicate which of these items you or other members of your household currently use (can select several alternatives)" and "Do you hand wash any of your laundry?" by country. (Person-based survey data, $\mathrm{N}=1111$ respondents, weighted).

\begin{tabular}{cccccccc}
\hline & & China & Germany & Japan & UK & USA & Total \\
\hline Top-loading washing machine & Own & $28 \%$ & $18 \%$ & $64 \%$ & $8 \%$ & $65 \%$ & $46 \%$ \\
& Use & $25 \%$ & $16 \%$ & $63 \%$ & $6 \%$ & $60 \%$ & $43 \%$ \\
Front-loading washing machine & Own & $35 \%$ & $71 \%$ & $12 \%$ & $69 \%$ & $23 \%$ & $33 \%$ \\
& Use & $29 \%$ & $62 \%$ & $11 \%$ & $64 \%$ & $17 \%$ & $28 \%$ \\
Combination washer-dryer & Own & $29 \%$ & $12 \%$ & $21 \%$ & $18 \%$ & $5 \%$ & $15 \%$ \\
& Use & $27 \%$ & $6 \%$ & $20 \%$ & $16 \%$ & $3 \%$ & $12 \%$ \\
Twin tub washing machine & Own & $13 \%$ & $5 \%$ & $4 \%$ & $2 \%$ & $6 \%$ & $7 \%$ \\
& Use & $11 \%$ & $2 \%$ & $3 \%$ & $1 \%$ & $3 \%$ & $4 \%$ \\
At-home dry cleaning & Own & $10 \%$ & $3 \%$ & $2 \%$ & $5 \%$ & $4 \%$ & $5 \%$ \\
& Use & $8 \%$ & $1 \%$ & $2 \%$ & $2 \%$ & $2 \%$ & $3 \%$ \\
Shared washing machine (laundromat) & Use & $6 \%$ & $8 \%$ & $10 \%$ & $8 \%$ & $13 \%$ & $10 \%$ \\
Hand wash some laundry & Use & $96 \%$ & $55 \%$ & $65 \%$ & $52 \%$ & $54 \%$ & $64 \%$ \\
Tumble dryer & Own & $14 \%$ & $27 \%$ & $6 \%$ & $27 \%$ & $60 \%$ & $35 \%$ \\
Shared dryer (laundromat) & Use & $8 \%$ & $24 \%$ & $5 \%$ & $21 \%$ & $54 \%$ & $30 \%$ \\
Line drying outdoors & Use & $7 \%$ & $5 \%$ & $10 \%$ & $4 \%$ & $10 \%$ & $8 \%$ \\
& Own & $52 \%$ & $25 \%$ & $39 \%$ & $32 \%$ & $13 \%$ & $28 \%$ \\
Line drying indoors & Use & $51 \%$ & $20 \%$ & $38 \%$ & $27 \%$ & $10 \%$ & $26 \%$ \\
& Own & $56 \%$ & $40 \%$ & $35 \%$ & $39 \%$ & $21 \%$ & $34 \%$ \\
& Use & $53 \%$ & $37 \%$ & $34 \%$ & $38 \%$ & $19 \%$ & $32 \%$ \\
\hline
\end{tabular}


Table 4. Examples of diary study participants' washing machines typical for each of the countries.

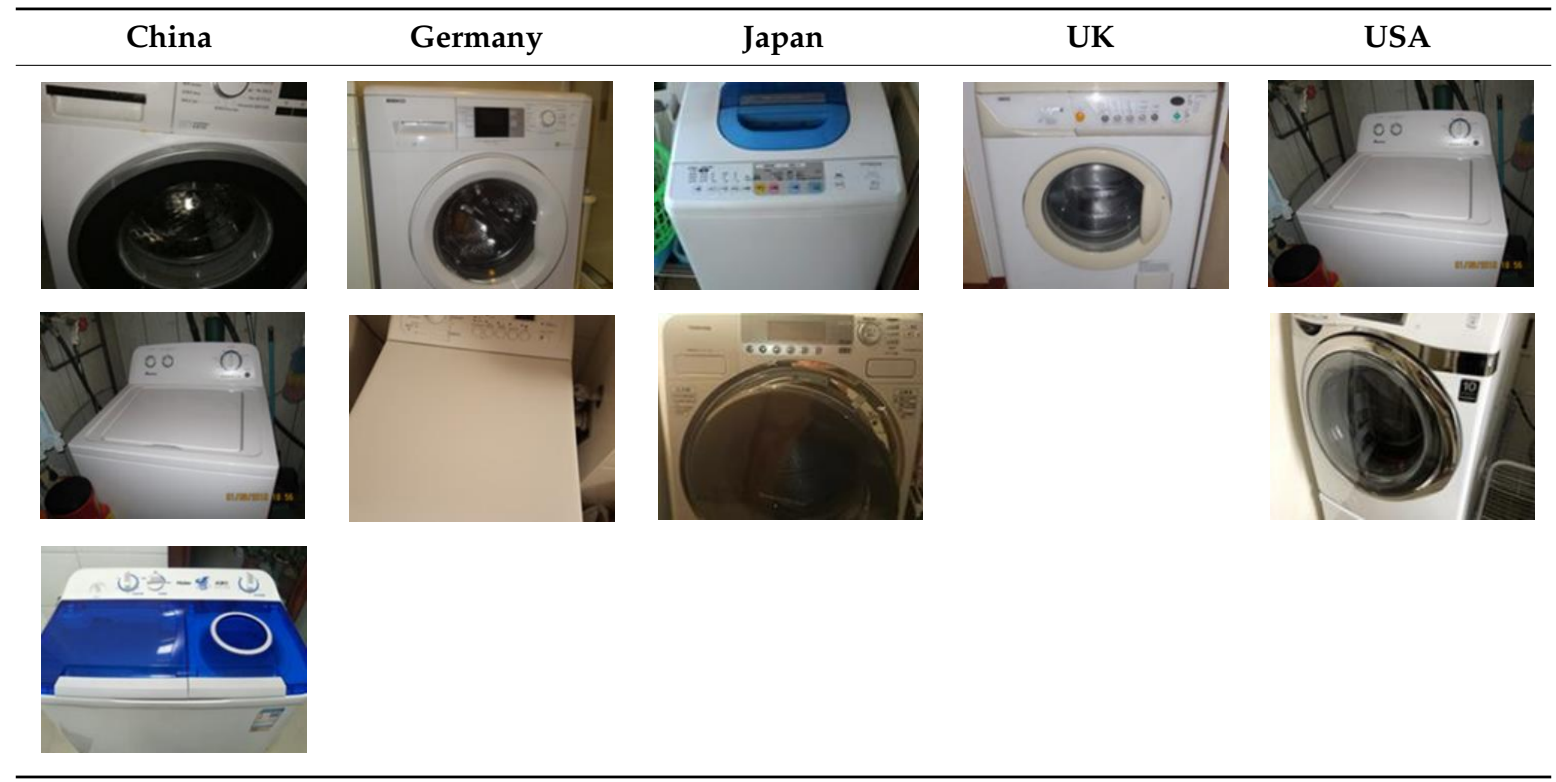

The diary results also confirm the survey data for washing machine types and ownership. The respondents used their own or a shared washing machine in the household (i.e., family, flatmates) for almost all the registered machine-washing activities. Almost all the US respondents used laundry dryers at least sometimes, while only slightly over half of the UK and German respondents did that, and less than half of Chinese and Japanese.

During the four weeks, 1902 cleaning activities and 1351 drying activities were registered by the participants (Table 5). Similar to the survey results, the diary data indicate that China differs from the other countries with a higher occurrence of washing by hand, but also with more dry cleaning. The drying practices follow the survey data as well; the USA stands out with a much higher use of clothes dryers.

Table 5. Laundry activities separated by cleaning and drying activities in diary study (diary study, $\mathrm{N}=3253$ activities, data not weighted).

\begin{tabular}{lcccccc}
\hline & China & Germany & Japan & UK & USA & Total \\
\hline Cleaning activities N & 444 & 330 & 494 & 359 & 275 & 1902 \\
Machine Wash & $40 \%$ & $81 \%$ & $71 \%$ & $83 \%$ & $74 \%$ & $68 \%$ \\
Hand Wash & $37 \%$ & $11 \%$ & $21 \%$ & $10 \%$ & $13 \%$ & $20 \%$ \\
Dry cleaning & $23 \%$ & $8 \%$ & $8 \%$ & $7 \%$ & $12 \%$ & $12 \%$ \\
Drying activities N & 271 & 283 & 333 & 245 & 219 & 1351 \\
Dried Clothes in a Tumble Dryer & $26 \%$ & $26 \%$ & $8 \%$ & $42 \%$ & $73 \%$ & $32 \%$ \\
Dried clothes on a line: & & & & & & \\
$\quad$ Outdoors & $39 \%$ & $1 \%$ & $56 \%$ & $21 \%$ & $1 \%$ & $26 \%$ \\
$\quad$ Indoors in a non-heated room & $25 \%$ & $14 \%$ & $18 \%$ & $7 \%$ & $2 \%$ & $14 \%$ \\
$\quad$ Indoors in a heated room & $10 \%$ & $57 \%$ & $17 \%$ & $30 \%$ & $21 \%$ & $27 \%$ \\
\hline
\end{tabular}

\subsubsection{Washing with Washing Machine}

Information about washing machines and laundering occasions based on survey and diary data is given in Table 6.

Washing machines in all five countries are rather large, with average capacity of over $6 \mathrm{~kg}$. Large washing machines and clothes dryers enable washing seldom and a lot of laundry at once, but this is not exploited by the consumers, as less than $70 \%$ of the loads are full, with the average 
washing load being $76 \%$. About one fifth to one quarter of the washing cycles in China are added to by additional prewash and/or extra rinse or spin cycles.

Table 6. Information about washing machines and laundering occasions based on survey and diary data.

\begin{tabular}{|c|c|c|c|c|c|c|}
\hline Washing Machine Details & China & Germany & Japan & UK & USA & Total \\
\hline $\begin{array}{c}\text { Maximum capacity of washing machine (mean kg), } \\
\text { diary data }\end{array}$ & 7.7 & 6.5 & 7.2 & 6.7 & $(7.6) *$ & 7.2 \\
\hline $\begin{array}{c}\text { Average Maximum Spinning Speed of Washing } \\
\text { Machine (rpm), diary data }\end{array}$ & 929 & 1365 & $(456)^{*}$ & 1266 & $(731)^{*}$ & 1069 \\
\hline $\begin{array}{c}\text { Average age of top-loading washing machined, } \\
\text { survey data }\end{array}$ & 3.1 & 5.5 & 6.8 & 2.1 & 5.5 & 5.5 \\
\hline $\begin{array}{l}\text { Average age of front-loading washing machined, } \\
\text { survey data }\end{array}$ & 3.1 & 5.2 & 4.9 & 4.6 & 5.0 & 4.6 \\
\hline $\begin{array}{c}\text { Average age of combination washer-dryer, } \\
\text { survey data }\end{array}$ & 2.1 & 2.9 & 4.4 & 3.7 & 2.6 & 3.1 \\
\hline $\begin{array}{c}\text { Average age of twin-tub washing machine, } \\
\text { survey data }\end{array}$ & 2.8 & - & 9.4 & - & 3.6 & 4.2 \\
\hline Average Age of Washing Machine (Years), diary data & 3.1 & 4.9 & 9.1 & 4.5 & 6.0 & 5.4 \\
\hline Average Temperature (Celsius), diary data & 31.1 & 42.9 & 20.2 & 42.3 & 25.5 & 33.5 \\
\hline Median Temperature (Celsius), diary data & 35 & 40 & 15 & 40 & 22 & 38 \\
\hline Pre-wash used & $20 \%$ & $5 \%$ & $4 \%$ & $4 \%$ & $6 \%$ & $7 \%$ \\
\hline Extra rinse/wash/spin & $26 \%$ & $7 \%$ & $1 \%$ & $6 \%$ & $6 \%$ & $8 \%$ \\
\hline Time Taken to complete cycle-average minutes & 55.5 & 82.7 & 40.8 & 81.2 & 36.0 & 59.7 \\
\hline Time Taken to complete cycle-Median minutes & 45 & 60 & 35 & 60 & 31 & 45 \\
\hline Average Spin Speed (rpm) & 955.1 & 1152.1 & 474.0 & 1117.0 & 585.3 & 932.7 \\
\hline Median Spin Speed (rpm) & 800 & 1200 & 90 & 1200 & 615 & 1000 \\
\hline Full load & $22 \%$ & $68 \%$ & $56 \%$ & $67 \%$ & $64 \%$ & $58 \%$ \\
\hline Half load & $57 \%$ & $25 \%$ & $34 \%$ & $28 \%$ & $29 \%$ & $33 \%$ \\
\hline A few small items & $21 \%$ & $7 \%$ & $10 \%$ & $5 \%$ & $6 \%$ & $9 \%$ \\
\hline Average filling grade & $55 \%$ & $82 \%$ & $75 \%$ & $82 \%$ & $80 \%$ & $76 \%$ \\
\hline
\end{tabular}

* The washing machine capacity in the US is usually given in volume (cubic feet), and therefore the laundry weight has been estimated. Additionally, many top-loading machines in the US and Japan do not report spin-drying speed in rpm but used scales instead (for example, $0-3$ ).

The average ages of washing machines vary between countries and types of machines. The newest machines are registered in China. In total, the average age is around 5 years, except for washer-dryers that are on average 3 years.

As seen in Table 6, the average washing temperatures varied between $20^{\circ} \mathrm{C}$ and $43{ }^{\circ} \mathrm{C}$ between countries. The warmest washing temperatures are found in Europe at about $40^{\circ} \mathrm{C}$, followed by China $\left(30^{\circ} \mathrm{C}\right)$, and the lowest average temperatures were reported in the US and in Japan. When comparing the washing loads by fibre content, the average value for all four main fibre categories varies between 28.5 and $33.5^{\circ} \mathrm{C}$, and therefore average washing temperature of 30 degrees is used in further calculations that compare fibre types.

In Europe, it is common to use frontloading machines with an internal water heater. These machines have also more efficient spin-drying capacities than the top-loading machines, and thus Japan, China and US would benefit of washing machines with higher spin-drying speed, which is also one of the strategies suggested by Bain et al. [12] for reducing the environmental impacts of laundering, as discussed in the introduction.

\subsubsection{Washing by Hand}

Table 7 gives information about hand washing practices including the temperature and amount of water based on laundry diary data. Hand washing practices are likely to vary more than machine washing but even if the data have some limitations, it is important because, previously, very little data have been available. 
Table 7. Hand wash details (diary data, not weighted).

\begin{tabular}{ccccccc}
\hline Hand Wash Details & China & Germany & Japan & UK & USA & Total \\
\hline Average Temperature (Celsius) & 30.4 & 31.6 & 31.8 & 37.4 & 31.5 & 30.4 \\
Rinse water temp.- -hot & $5 \%$ & $4 \%$ & $0 \%$ & $0 \%$ & $9 \%$ & $4 \%$ \\
Rinse water temp-—warm & $25 \%$ & $32 \%$ & $31 \%$ & $22 \%$ & $19 \%$ & $27 \%$ \\
Rinse water temp.-lukewarm & $34 \%$ & $52 \%$ & $20 \%$ & $44 \%$ & $16 \%$ & $30 \%$ \\
Rinse water temp.-cold & $36 \%$ & $12 \%$ & $49 \%$ & $33 \%$ & $56 \%$ & $39 \%$ \\
Average water use Litres/cycle & 16.3 & 14.2 & 7.0 & 5.2 & 7.7 & 12.4 \\
Water use litres/kg laundry & 8.15 & 7.1 & 3.5 & 2.6 & 3.85 & 6.2 \\
Energy use kwh/kg laundry * & 0.189 & 0.165 & 0.081 & 0.091 & 0.089 & 0.144 \\
\hline
\end{tabular}

* Calculated from heat capacity of water which is $4.184 \mathrm{~J} / \mathrm{gram} /$ Celsius.

The average hand washing temperature in all the five countries is between 30 and 40 degrees Celsius. The hand washing temperature in Japan and the USA is higher than in machine wash, while in Germany and the UK, the hand washing temperature is lower. In China, about $30{ }^{\circ} \mathrm{C}$ is used in both ways of laundering. In further calculations, it was assumed that hand washing is conducted at $30{ }^{\circ} \mathrm{C}$, except for the UK, where the average was higher $\left(40^{\circ} \mathrm{C}\right)$. It is most common to use cold water for rinsing hand-washed laundry, followed by lukewarm water, and then warm water. Very few respondents used hot water for rinsing.

The respondents estimated they used on average $12.4 \mathrm{~L}$ of water/cycle. It may have been difficult to estimate the amounts, especially if using running water for rinsing. The total weight for each hand wash laundry load is not known, but based on registrations and photos of activity levels, it seems that most only included a few items, and therefore this laundry load was estimated to be $2 \mathrm{~kg}$. Information about the use of detergents is included in Appendix A Tables A6 and A7.

\subsubsection{Dry Cleaning}

An analysis was made of diary data on dry cleaning activities. In total, 59\% of the registered dry cleaning activities lacked information about the used process, as the respondents did not know which kind of process the garments went through (Table 8). Chinese respondents registered the most dry cleaning activities ( $45 \%$ of all cases) and had the best knowledge on which processes were used.

Table 8. Dry cleaning details (diary data, not weighted).

\begin{tabular}{ccccccc}
\hline Dry Cleaning Details & China & Germany & Japan & UK & US & Total \\
\hline N & 98 & 15 & 36 & 20 & 29 & 198 \\
Perchloroethylene (a.k.a. PERC or PCE) & $28 \%$ & $7 \%$ & $11 \%$ & $10 \%$ & $7 \%$ & $18 \%$ \\
Trichloroethylene (a.k.a. TCE) & $16 \%$ & $0 \%$ & $8 \%$ & $15 \%$ & $3 \%$ & $12 \%$ \\
Professional Wet Cleaning & $14 \%$ & $7 \%$ & $3 \%$ & $20 \%$ & $7 \%$ & $11 \%$ \\
D5 (a.k.a. 'liquid silicone' e.g., GreenEarth) & $4 \%$ & $0 \%$ & $0 \%$ & $10 \%$ & $0 \%$ & $3 \%$ \\
Hydrocarbons & $1 \%$ & $0 \%$ & $3 \%$ & $15 \%$ & $0 \%$ & $3 \%$ \\
Other & $1 \%$ & $7 \%$ & $8 \%$ & $5 \%$ & $14 \%$ & $5 \%$ \\
Don't know & $39 \%$ & $80 \%$ & $72 \%$ & $40 \%$ & $79 \%$ & $54 \%$ \\
\hline
\end{tabular}

Of the dry cleaning activities where the process was known, using perchloroethylene (PERC) was most common (39\%), followed by trichloroethylene (a.k.a. 'TCE') $(25 \%)$, professional wet cleaning $(24 \%)$, D5 (7\%) and hydrocarbons (5\%). In general, TCE is used to remove spots from garments before or after cleaning them in dry cleaning machines [72]. There were differences between countries. It was most common to use the harmful PERC and TCE processes in China, but a few of them were also registered in the other countries.

Based on the total estimate from all countries, it is most common to use PCE treatments, followed by TCE and wet cleaning. It was not possible to find a clear pattern on which processes were used on which materials, as both professional wet cleaning as well as more harmful cleaning processes with PERC and TCE were used for suits of all materials (cotton, wool and manmade). 


\subsubsection{Clothes Dryers}

Similar to washing machines, the capacities of clothes dryers are quite high, all being on average above $6 \mathrm{~kg}$ (Table 9). The longest tumble drying times can be found in Europe, and the shortest in China. In China and Japan, it is common to dry only a few items in the tumble dryer.

Table 9. Tumble drying details (diary data, not weighted).

\begin{tabular}{ccccccc}
\hline Tumble Dry Details & China & Germany & Japan & UK & USA & Total \\
\hline Average Maximum Capacity of Tumble Dryer $(\mathrm{kg})$ & 6.5 & 6.8 & 6.7 & 6.1 & 7.6 & 6.8 \\
Average Age of Tumble Dryer (Years) & 1.8 & 7.4 & 6.3 & 4.8 & 6.6 & 5.6 \\
Vented type & $60 \%$ & $5 \%$ & $20 \%$ & $25 \%$ & $91 \%$ & $45 \%$ \\
Condenser/washer-dryer & $40 \%$ & $95 \%$ & $80 \%$ & $75 \%$ & $9 \%$ & $55 \%$ \\
Average Time minutes & 26.4 & 108.9 & 44.0 & 84.4 & 44.3 & 61.8 \\
Median Time minutes & 10 & 115 & 30 & 60 & 41 & 45 \\
Full load & $10 \%$ & $38 \%$ & $12 \%$ & $52 \%$ & $58 \%$ & $45 \%$ \\
Half load & $54 \%$ & $55 \%$ & $41 \%$ & $45 \%$ & $37 \%$ & $44 \%$ \\
A few small items & $35 \%$ & $7 \%$ & $47 \%$ & $3 \%$ & $5 \%$ & $11 \%$ \\
\hline
\end{tabular}

In the next sections, we give an overview of results for cleaning methods and frequencies of washing formal wear (suits, trousers and skirts), t-shirts/polo shirts/singlets, and socks/stockings. Suits were defined as having a jacket, and a pair of trousers or a skirt. Since both data from the survey and laundry diaries are used, the source will be given in each table/figure.

\subsection{Clothing Specific Data}

We asked the survey respondents how they wash the specific clothing items. The answering alternatives included washing in the machine, hand washing, dry cleaning and two combinations of the three methods, so that respondents could choose, for example, "Sometimes hand wash and sometimes dry clean". These answers have been divided between the answering alternatives equally as if the garments then are washed every second time with one of the alternatives. The answering divisions for formal wear are given in Figure 1, t-shirts in Figure 2 and socks/stockings in Figure 3.

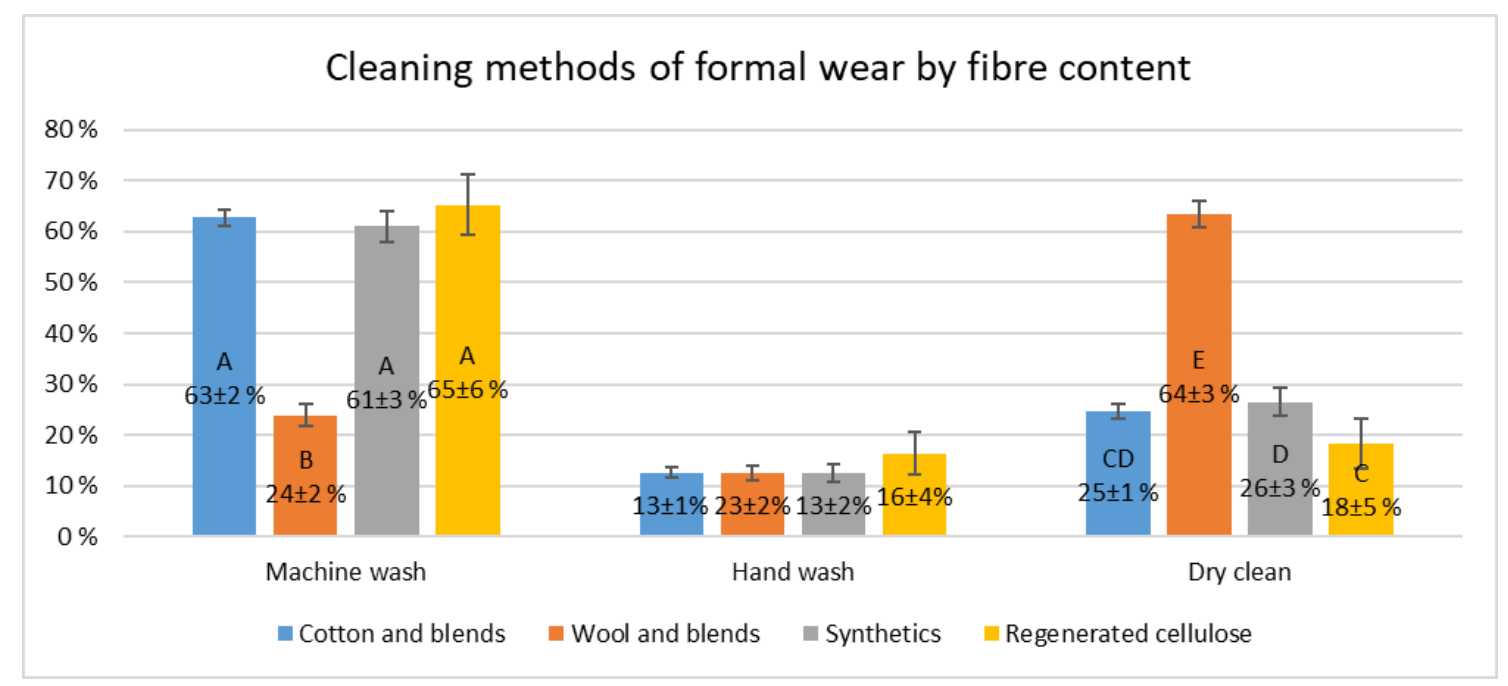

Figure 1. Cleaning methods of formal wear by fibre content. Means with $95 \%$ confidence intervals. Wardrobe survey data, $\mathrm{N}=5271$ garments. One-way ANOVAs per cleaning method: Machine wash: $\mathrm{F}(3,5267)=238.39, p<0.001$. Hand wash $\mathrm{F}(3,5267)=1.25, p=0.292$, dry clean: $\mathrm{F}(3,5267)=261.57$, $p<0.001$. Means with different letters are significantly different at $p<0.05$ probability level based on the Tukey HSD (honestly significant difference) test between cases. 


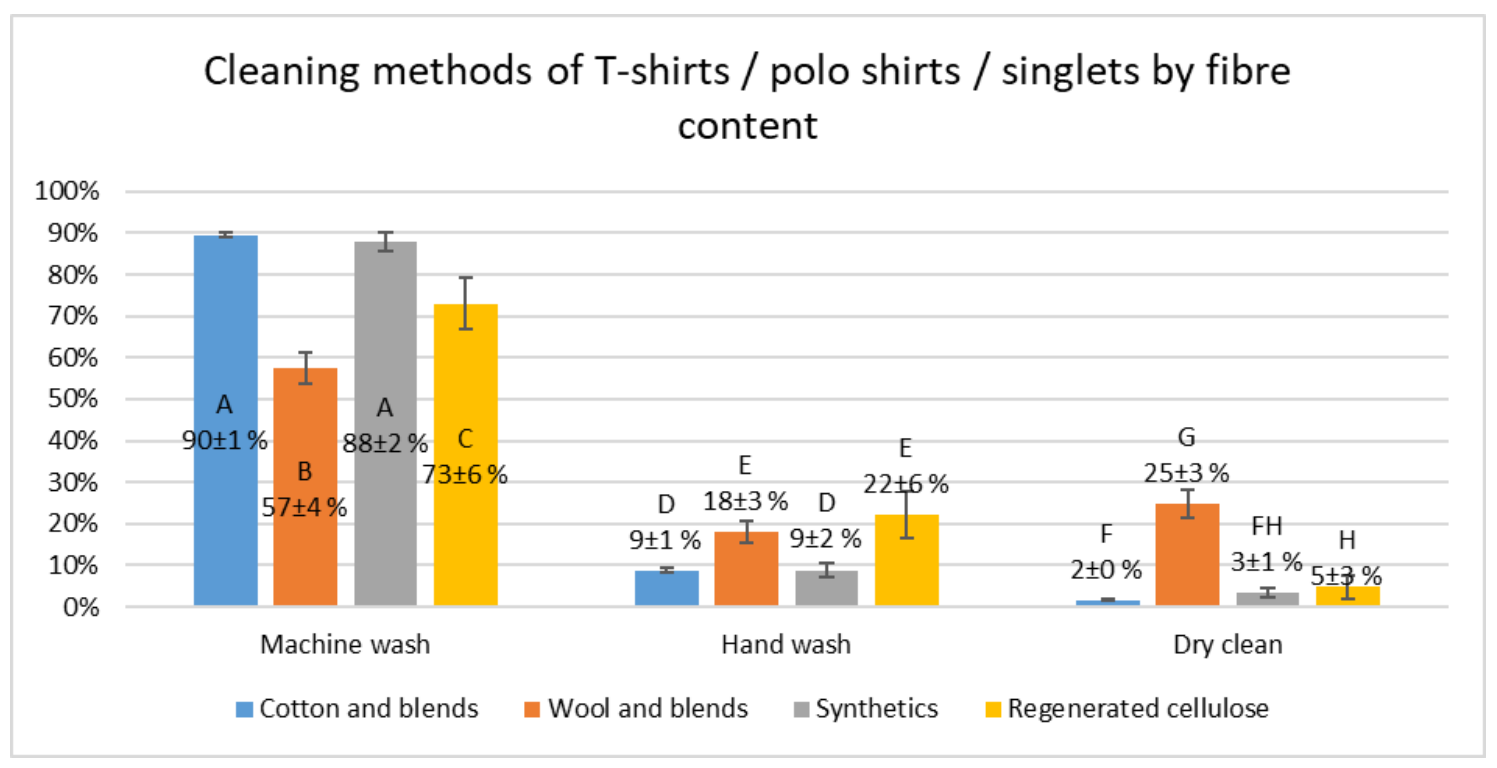

Figure 2. Cleaning methods of T-shirts/Polo shirts/singlets fibre content. Means with $95 \%$ confidence intervals. Wardrobe survey data, $\mathrm{N}=8369$ garments. One-way ANOVAs per cleaning method: Machine wash: $\mathrm{F}(3,8355)=193.43, p<0.001$, Hand wash: $\mathrm{F}(3,8355)=33.03, p<0.001$, dry clean: $\mathrm{F}(3,8355)=344.20, p<0.001$. Means with different letters are significantly different at $p<0.05$ probability level based on Tukey HSD test between cases.

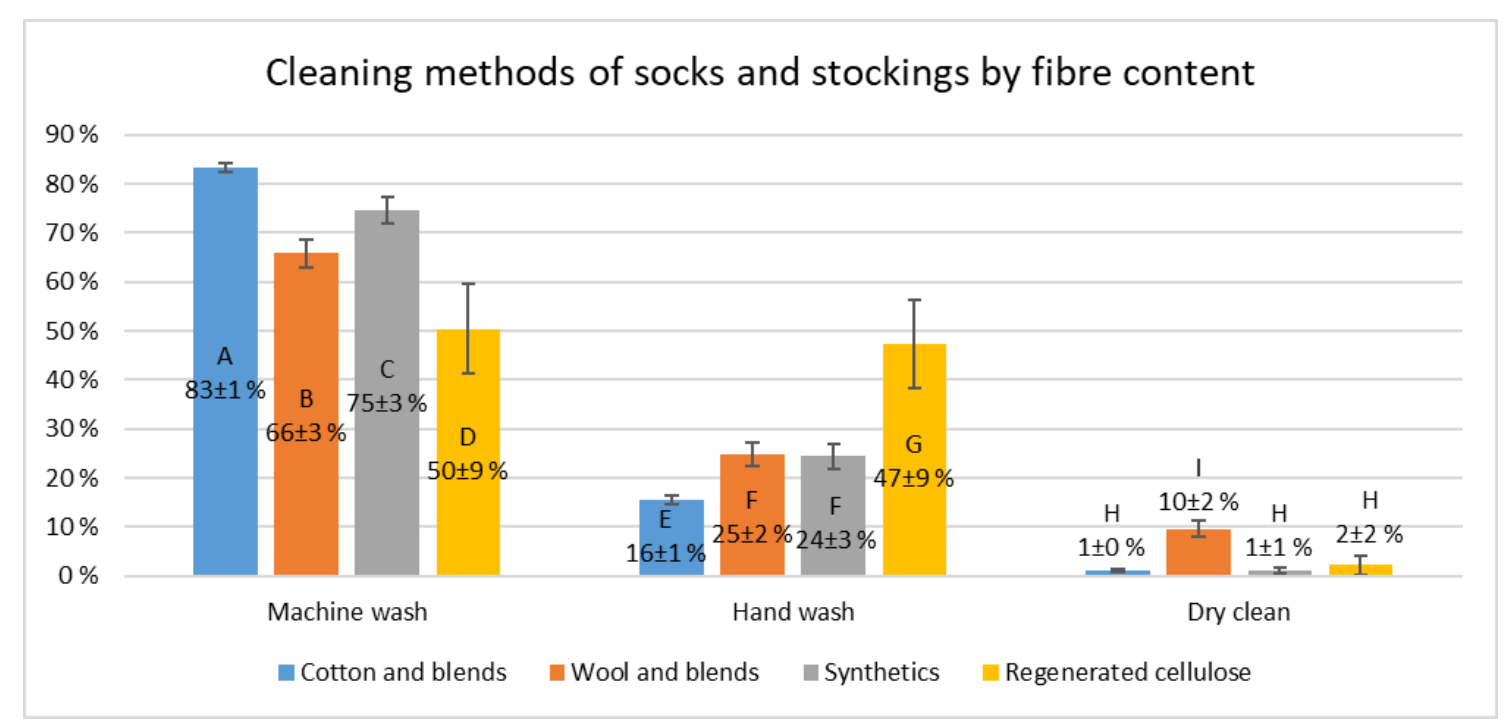

Figure 3. Cleaning methods of socks and stockings by fibre content. Means with $95 \%$ confidence intervals. Wardrobe survey data, $\mathrm{N}=8569$ garments. One-way ANOVAs per cleaning method: Machine wash: $\mathrm{F}(3,8565)=92.40, p<0.001$, Hand wash: $\mathrm{F}(3,8565)=55.78, p<0.001$, dry clean: $\mathrm{F}(3,8565)=121.48, p<0.001$. Means with different letters are significantly different at $p<0.05$ probability level based on the Tukey HSD test between cases.

When comparing the cleaning methods, we find many significant differences between the three garment types, fibre contents and countries. Formal wear is more often dry cleaned than t-shirts or socks. However, still over half of formal wear items made of cotton or man-made fibres are laundered in the washing machine, while the same figure for woollen formal wear is only one quarter (Figure 1). There are no significant differences between fibre contents for hand washing. Dry cleaning woollen formal wear is significantly more common than dry cleaning the other fibres, and it is least common to dry clean formal wear made of regenerated cellulose fibres, followed by cotton and blends. 
Figure 2 shows that the majority of $\mathrm{t}$-shirts/polo shirts/singlets are washed in a washing machine, but that there are some significant differences between the fibre types. Even though most woollen $\mathrm{t}$-shirts are washed in a machine, a greater share of them are dry cleaned than $\mathrm{t}$-shirts made of other materials. They are also more often washed by hand than cotton or synthetics, while the difference compared to regenerated cellulose $t$-shirts in hand washing is not significant.

Figure 3 and Table 10 show that washing socks and stockings in washing machine dominates, but it is not uncommon to wash them by hand either, especially in China (Table 11). There are significant differences between socks made of different materials. It is bit more common to wash wool and man-made materials by hand than cotton socks, and some woollen socks or stockings are also dry cleaned.

Table 10 gives laundering data for the same garment categories based on diary data. The laundry contents and cleaning methods are registered by laundry activity, not by garment, as they were in the survey data. Therefore, the figures are not exact for garments made of different materials, but it is possible to analyse laundry loads that included socks and separate them by different fibre contents. A washing load that contains both cotton socks and woollen formal wear is then registered for both garment and fibre categories. These figures are somewhat more uncertain in relation to the combinations of the type of garment and fibre content but give a realistic overview of the division between various laundry activities. It is not possible to give similar significance calculations for the diary data as we did for the survey data, because a laundry cycle containing cotton and socks will be compared with those cycles that do not contain cotton or socks, not other garments/fibres. An additional benefit of diary data is that they include information about drying methods, which were not included in the survey.

The laundering diary data for formal wear by fibre shows similar tendencies as the survey data, except for formal wear made of regenerated cellulose materials. Those are reported to be dry cleaned to a higher degree in the diary data than in the survey data. Diary data on cleaning t-shirts and socks give quite a different picture than the survey data. Washing them in a washing machine dominates for all included fibre types. This difference may be related to the occurrence of the cleaning events, where a much higher share of garments is being washed in the machine than taken to the dry cleaners during the registration period. It may also be that the wardrobe survey data captured many items that are not worn as frequently. Additionally, a large share of laundry loads included socks.

Table 11 compares the cleaning data between the five countries based on survey data, while Table 12 gives the same comparison based on diary data. The same three garment groups are included as previously. Tables show significant differences between countries in most studied cases. Cleaning in a washing machine dominates most cases, with a few exceptions. The survey data indicate that it is more common to dry clean formal wear in Japan, and wash socks by hand in China. On the other hand, the diary data indicate that a larger share of wash loads in Japan included formal wear than dry cleaning loads, while, in the US, both dry cleaning and washing formal wear in machines were about equally as common.

Hand washing all three garment types is more common in China than other countries based on both data sources. It is much more common to use clothes dryers in the US than in the other included countries. They are used especially seldomly in Japan. 
Table 10. Comparison of cleaning and drying methods between garments made of different fibres based on diary data. Percentage of laundry activities that included formal wear, t-shirts/Polo shirts/Singlets or socks/stockings by fibre content for (diary data, not weighted).

\begin{tabular}{|c|c|c|c|c|c|c|c|c|c|}
\hline \multirow{2}{*}{ Garment Category } & \multirow{2}{*}{ Fibre Content } & \multicolumn{3}{|c|}{ Cleaning Activities } & \multicolumn{4}{|c|}{ Drying Activities } & \multirow[b]{2}{*}{$\mathbf{N}$} \\
\hline & & Machine Wash & Hand-Wash & Dry Clean & Clothes Dryer & $\begin{array}{c}\text { Line Dried } \\
\text { Outdoors }\end{array}$ & $\begin{array}{c}\text { Line Dried in } \\
\text { Non-Heated Room }\end{array}$ & $\begin{array}{l}\text { Line Dried in } \\
\text { Heated Room }\end{array}$ & \\
\hline \multirow{4}{*}{ Formal wear } & Cotton and blends & $79 \%$ & $5 \%$ & $16 \%$ & $23 \%$ & $29 \%$ & $20 \%$ & $27 \%$ & 405 \\
\hline & Wool and blends & $44 \%$ & $5 \%$ & $51 \%$ & $19 \%$ & $23 \%$ & $21 \%$ & $37 \%$ & 159 \\
\hline & Synthetics & $85 \%$ & $3 \%$ & $12 \%$ & $12 \%$ & $40 \%$ & $23 \%$ & $25 \%$ & 259 \\
\hline & Reg. cellulose & $42 \%$ & $0 \%$ & $58 \%$ & $17 \%$ & $19 \%$ & $40 \%$ & $25 \%$ & 96 \\
\hline \multirow{4}{*}{ T-shirts } & Cotton and blends & $97 \%$ & $3 \%$ & $0 \%$ & $26 \%$ & $31 \%$ & $13 \%$ & $30 \%$ & 1093 \\
\hline & Wool and blends & $93 \%$ & $3 \%$ & $3 \%$ & $18 \%$ & $18 \%$ & $21 \%$ & $42 \%$ & 168 \\
\hline & Synthetics & $99 \%$ & $1 \%$ & $0 \%$ & $22 \%$ & $38 \%$ & $17 \%$ & $24 \%$ & 638 \\
\hline & Reg. cellulose & $95 \%$ & $3 \%$ & $2 \%$ & $26 \%$ & $27 \%$ & $26 \%$ & $21 \%$ & 249 \\
\hline \multirow{4}{*}{ Socks } & Cotton and blends & $94 \%$ & $6 \%$ & $0 \%$ & $21 \%$ & $34 \%$ & $17 \%$ & $28 \%$ & 1245 \\
\hline & Wool and blends & $93 \%$ & $7 \%$ & $0 \%$ & $11 \%$ & $23 \%$ & $24 \%$ & $42 \%$ & 186 \\
\hline & Synthetics & $98 \%$ & $2 \%$ & $0 \%$ & $16 \%$ & $41 \%$ & $19 \%$ & $24 \%$ & 406 \\
\hline & Reg. cellulose & $96 \%$ & $4 \%$ & $0 \%$ & $15 \%$ & $25 \%$ & $32 \%$ & $28 \%$ & 297 \\
\hline
\end{tabular}


Table 11. Comparison of cleaning methods between countries. Means with $95 \%$ confidence intervals and one-way ANOVA. Unweighted wardrobe survey data, Formal wear N = 5452, T-shirts $\mathrm{N}=8621$, Socks and stockings $\mathrm{N}=8989$. Different letters indicate significant difference at $p<0.05$ probability level between countries based on Tukey HSD post-hoc test within each garment category.

\begin{tabular}{ccccc}
\hline Garment Category & Country & Machine Wash & Hand Wash & Dry Clean \\
\hline & China & $53 \pm 2 \% \mathrm{~A}$ & $23 \pm 2 \% \mathrm{E}$ & $24 \pm 2 \% \mathrm{H}$ \\
& Germany & $68 \pm 3 \% \mathrm{~B}$ & $6 \pm 1 \% \mathrm{~F}$ & $26 \pm 3 \% \mathrm{H}$ \\
& Japan & $32 \pm 2 \% \mathrm{C}$ & $9 \pm 1 \% \mathrm{~F}$ & $59 \pm 2 \% \mathrm{I}$ \\
Formal wear & UK & $70 \pm 3 \% \mathrm{~B}$ & $7 \pm 2 \% \mathrm{~F}$ & $23 \pm 3 \% \mathrm{H}$ \\
& USA & $60 \pm 3 \% \mathrm{D}$ & $14 \pm 2 \% \mathrm{G}$ & $26 \pm 3 \% \mathrm{H}$ \\
& Total & $54 \pm 1 \%$ & $13 \pm 1 \%$ & $33 \pm 1 \%$ \\
& ANOVA & $\mathrm{F}(4,5447)=135,20$, & $\mathrm{F}(4,5447)=72.53$, & $\mathrm{F}(4,5447)=170.28$, \\
& $p<0.001$ & $p<0.001$ & $p<0.001$ \\
\hline China & $56 \pm 2 \% \mathrm{~A}$ & $37 \pm 2 \% \mathrm{D}$ & $7 \pm 1 \% \mathrm{G}$ \\
& Germany & $94 \pm 1 \% \mathrm{~B}$ & $4 \pm 1 \% \mathrm{E}$ & $2 \pm 1 \% \mathrm{H}$ \\
& Japan & $93 \pm 1 \% \mathrm{~B}$ & $4 \pm 1 \% \mathrm{E}$ & $3 \pm 1 \% \mathrm{H}$ \\
& UK & $92 \pm 1 \% \mathrm{~B}$ & $5 \pm 1 \% \mathrm{E}$ & $3 \pm 1 \% \mathrm{H}$ \\
& USA & $88 \pm 1 \% \mathrm{C}$ & $8 \pm 1 \% \mathrm{~F}$ & $4 \pm 1 \% \mathrm{H}$ \\
& Total & $\mathrm{F}(4, \pm 1 \%$ & $10 \pm 1 \%$ & $3 \pm 0.4 \%$ \\
& ANOVA & $p<016)=437.65$, & $\mathrm{F}(4,8616)=469.46$, & $\mathrm{F}(4,8616)=18.89$, \\
& China & $38 \pm 2 \% \mathrm{~A}$ & $60 \pm 2 \% \mathrm{D}$ & $2 \pm 1 \% \mathrm{GH}$ \\
& Germany & $91 \pm 1 \% \mathrm{~B}$ & $7 \pm 1 \% \mathrm{EF}$ & $2 \pm 1 \% \mathrm{G}$ \\
& Japan & $91 \pm 1 \% \mathrm{~B}$ & $7 \pm 1 \% \mathrm{EF}$ & $2 \pm 1 \% \mathrm{G}$ \\
& UK & $93 \pm 1 \% \mathrm{~B}$ & $6 \pm 1 \% \mathrm{E}$ & $1 \pm 1 \% \mathrm{G}$ \\
& USA & $88 \pm 1 \% \mathrm{C}$ & $9 \pm 1 \% \mathrm{~F}$ & $3 \pm 1 \% \mathrm{H}$ \\
& $80 \pm 1 \%$ & $18 \pm 1 \%$ & $2 \pm 0.3 \%$ \\
& Total & $\mathrm{F}(4,8984)=973.69$, & $\mathrm{F}(4,8984)=1111.09$, & $\mathrm{F}(4,8984)=4.44$, \\
& ANOVA & $p<0.001$ & $p<0.001$ & $p<0.005$ \\
\hline
\end{tabular}

Table 12. Comparison of cleaning and drying methods between countries based on diary data. Mean values calculated from laundry activities that included the specified clothing item. Percentage by cleaning or drying activity per country. The Number of activities that contained: Formal wear: $\mathrm{N}=476$, T-shirts: $\mathrm{N}=1124$, Socks and stockings: $\mathrm{N}=1290$.

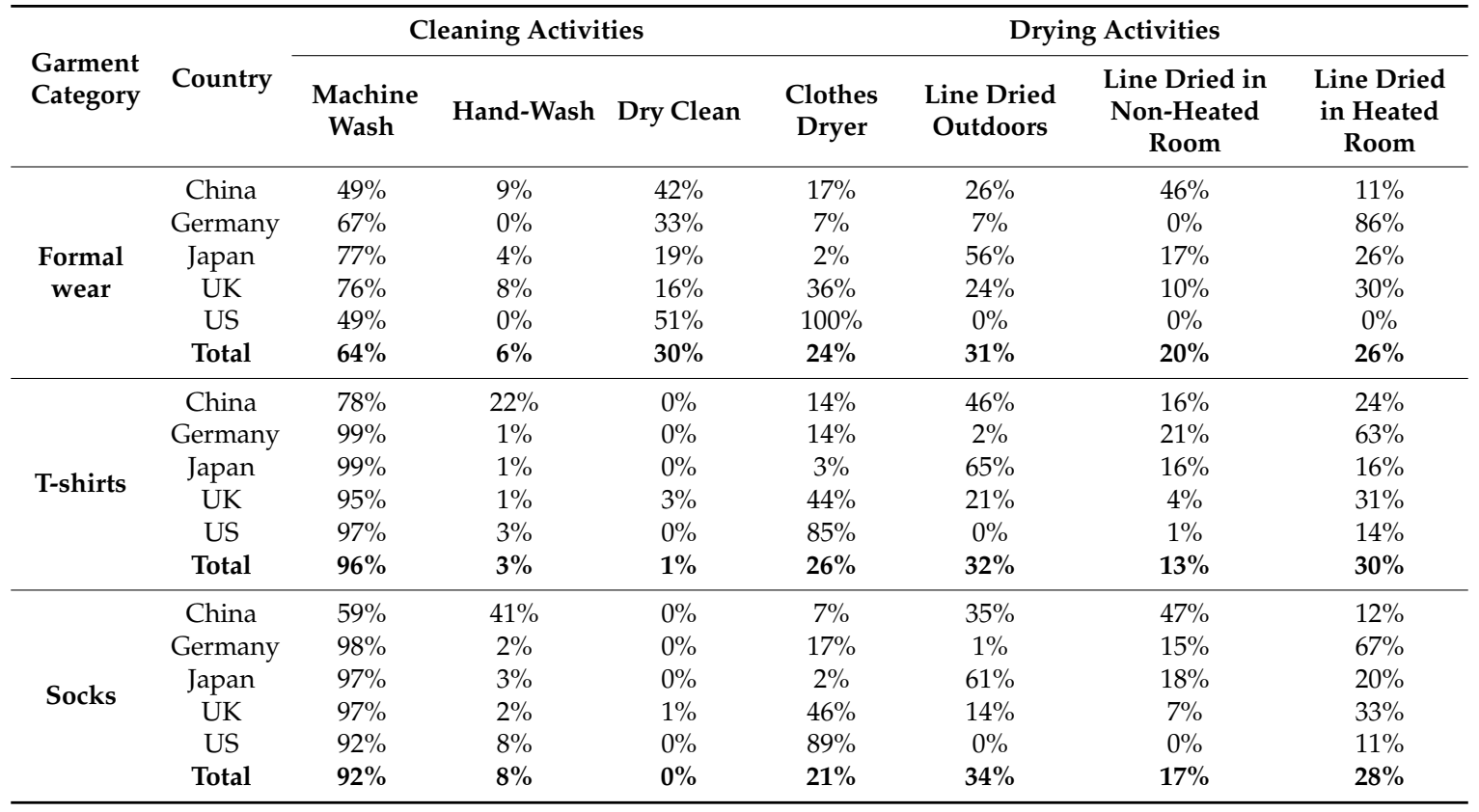




\section{Cleaning Frequencies}

In addition to the cleaning method, the frequency of cleaning is of great importance when the environmental impact of use is calculated. We asked the wardrobe survey respondents "How often do you or someone else typically wash or dry clean this item?". The answering frequencies are shown in Figure 4. There are great variations between the garment groups as well as the fibre content. Socks and stockings are washed most frequently, followed by t-shirts/polos/singlets, while formal wear is washed least frequently. Woollen garments are washed less frequently than garments made of other fibres.

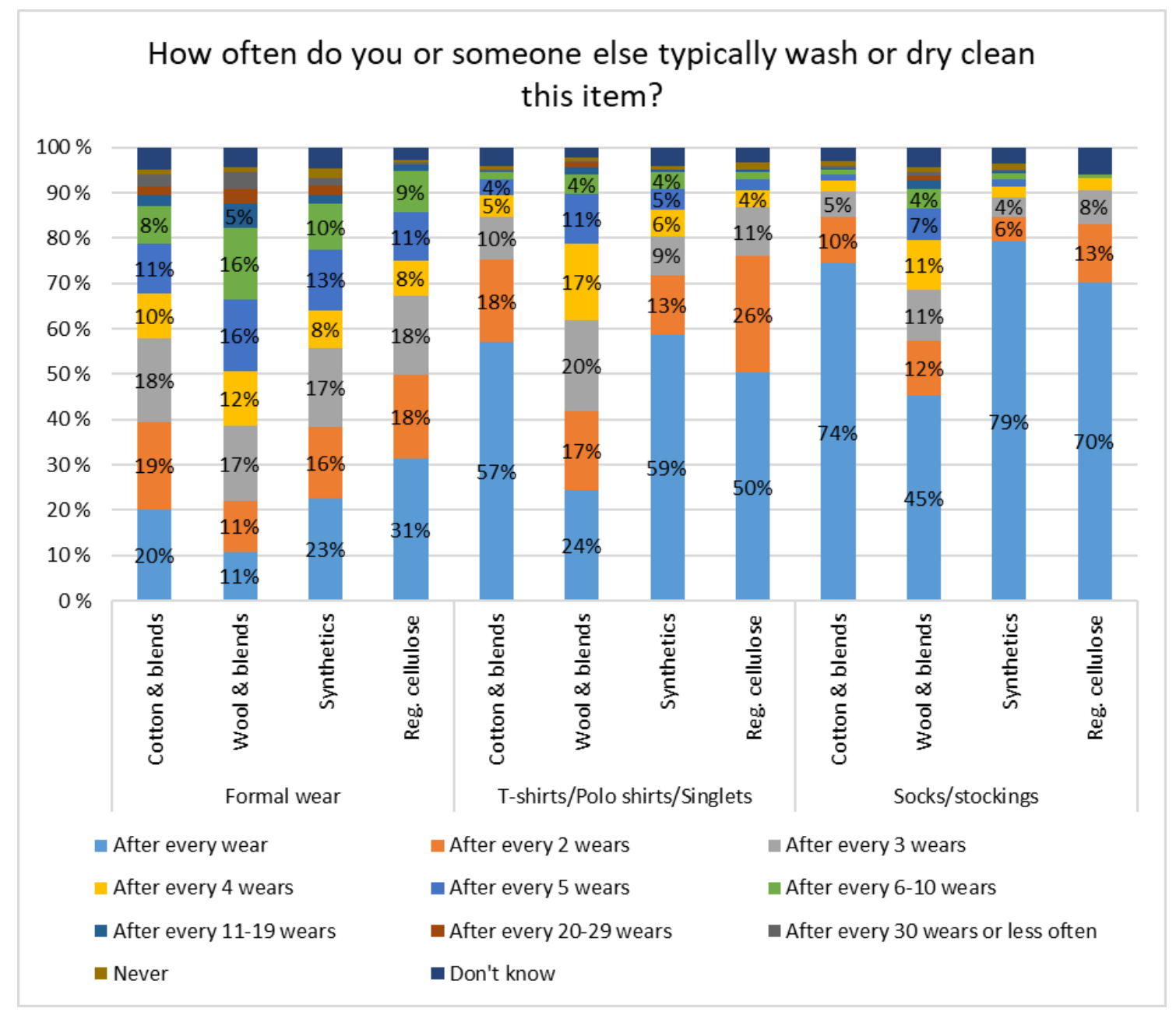

Figure 4. The Number of days garments are worn before cleaning by fibre content. Frequencies including all five countries. (wardrobe survey data. $\mathrm{N}=23,392$ garments).

In order to analyse these variations further, we calculated the average number of wears before cleaning. The answering category "Over 30 wears" was coded to 50 wears. "Never" and "Don't know" answers were excluded from calculations.

Our analysis of cleaning frequency shows that those made of wool are washed significantly less often than similar garments made of other fibres in all three garment groups (Figure 5). There is no significant difference in laundering frequency between cotton and synthetics in any of the analysed garment types, and regenerated cellulose only differs significantly from those two fibres in the cleaning frequency of formal wear, being washed the most frequently.

Woollen socks and stockings are used almost twice as long between cleaning than similar products made of other materials in all five countries, while woollen t-shirts are used 1.5 days longer than $\mathrm{t}$-shirt of other materials. 


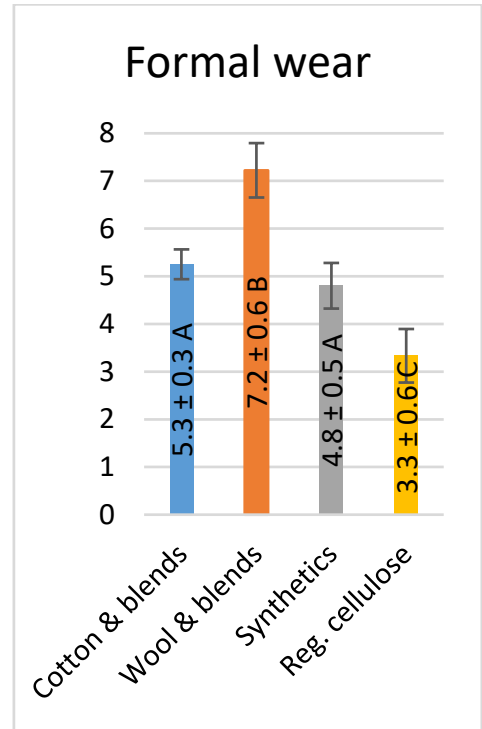

(a)

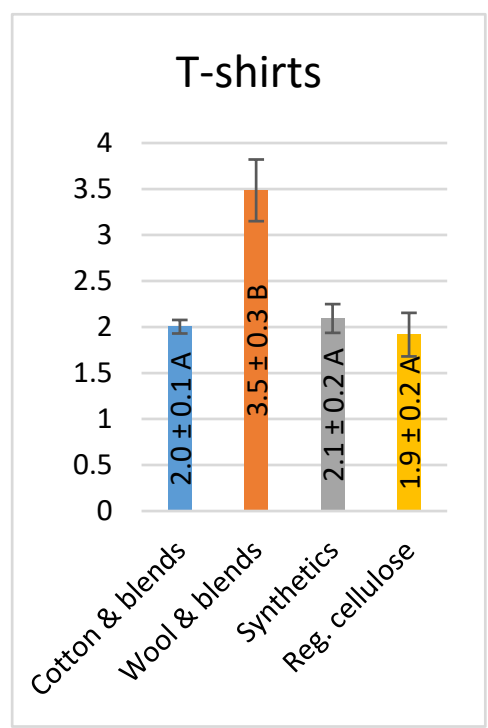

(b)

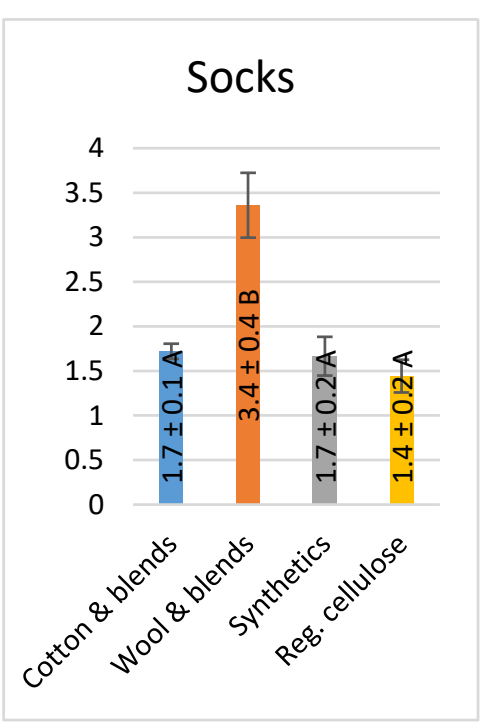

(c)

Figure 5. $(\mathbf{a}-\mathbf{c})$. Mean number of days garments are worn between cleaning by fibre content of (a) formal wear (suits, trousers and skirts), (b) T-shirts, polo shirts and singlets, and (c) socks and stockings. Mean value with $95 \%$ confidence intervals given in figures. Means with different letters are significantly different between groups at $p<0.05$ probability level based on the Tukey HSD test. Wardrobe survey data. (a) $\mathrm{N}=5295$ garments. One-way $\operatorname{ANOVA~} \mathrm{F}(3,5291)=22.54, p<0.001$. (b) $\mathrm{N}=8384$ garments. One-way $\operatorname{ANOVAF}(3,8380)=37.27, p<0.001$. (c) $\mathrm{N}=8583$ garments. One-way ANOVA $F(3,8579)=54.38, p<0.001$.

Suits are worn on average 5.5 times before cleaning them, but the laundering frequency varies greatly from after every wear to over 30 wears, or even never. The respondents who answered never may be following advice given in classic style guide books for men, that suggest that suits should be aired and brushed instead of cleaning [73].

The difference in practices is larger between countries than between fibre types. When only looking at fibre content and excluding the country, wool suits are cleaned significantly more seldomly than cotton ( 2.5 days) or man-made (3.3 days) suits, while the difference between cotton and man-made suits is not significant.

When comparing the cleaning frequencies between countries, we found significant differences in cleaning for formal wear (Figure 6), but no differences in the cleaning of next-to-skin garments (Figures A1 and A2 in Appendix A). Japanese clean their formal wear most seldomly (after 8.8 wears, followed by Germans and the British (5.6-6.1 wears), while Chinese and American consumers clean them most frequently (after 3.3-3.6 wears). A detailed breakdown of wear frequencies per country with corresponding $\mathrm{N}$ for each category is given in Appendix A Table A1.

\subsection{Environmental Impacts}

This section combines the data from previous sections with other literature sources to estimate environmental impacts for the selected example of garment types in different fibres used in different countries. We calculated the energy and water use based on the available data and indicate the $\mathrm{CO}_{2}$ emissions based on the electricity mix for each country as well as the global average. The results do not represent the full life cycle impacts as assessed elsewhere by the authors for woollen garments [6], as the production phase is excluded.

More detailed information on background data, sources and the selection of figures is given in Appendix A. Some of the aspects have several potential data sources. For example, the cleaning method was included both in the survey and diary study. In general, the different sources supported 
each other, and survey data were chosen for better representation. One exception was made for the cleaning of socks, where diary data were chosen for further analysis because it seemed more realistic.

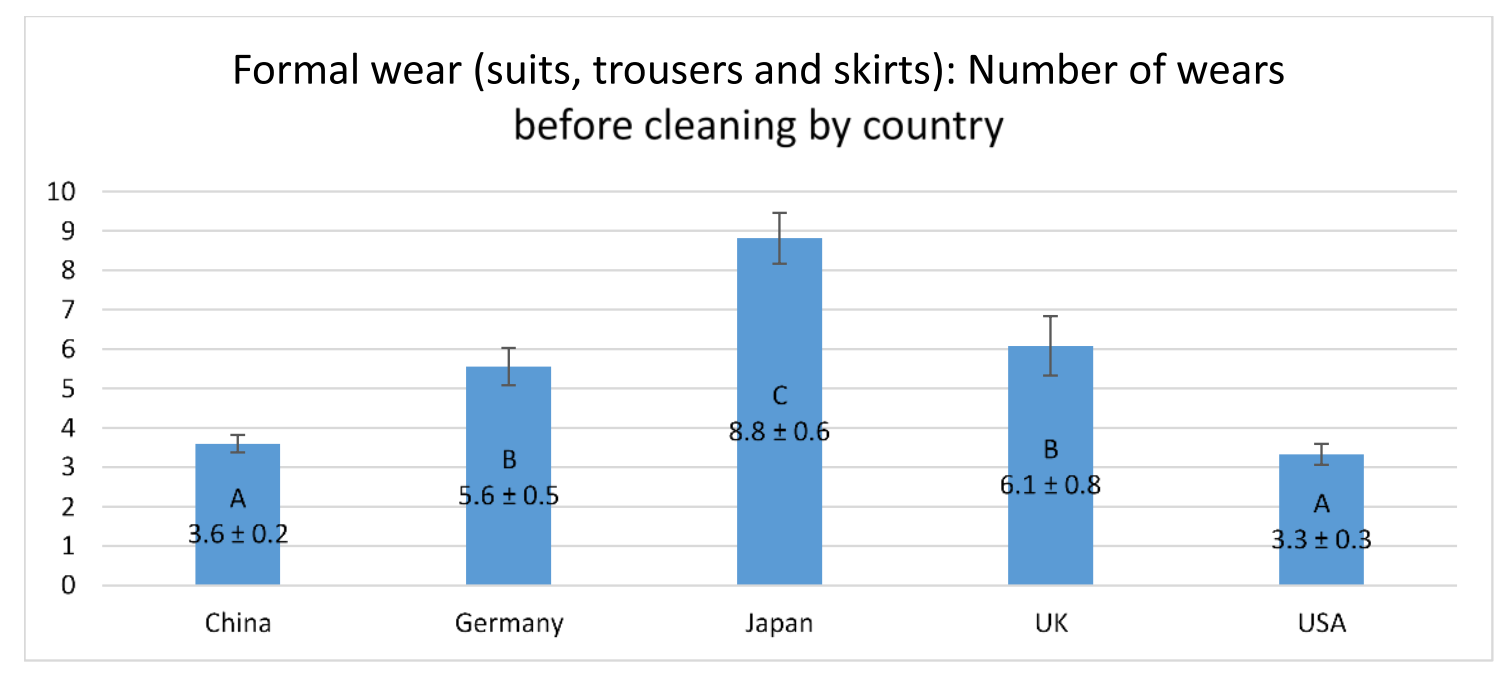

Figure 6. Mean number of days formal wear is worn between cleaning by country. Mean with $95 \%$ confidence intervals. Wardrobe survey data, $N=5482$ garments. One-way ANOVA F $(4,5477)=88.80$, $p<0.001$. Means with different letters are significantly different at $p<0.05$ probability level based on the Tukey HSD test between cases.

\subsubsection{Energy Use and Related $\mathrm{CO}_{2}$ Emissions}

Energy use for formal wear for one wear is given in Figure 7, which indicates that even though there are large differences between the fibre types, the differences between countries are even greater. The US stands out as the country where formal attire is the most energy-intensive to keep clean, as energy use for one wear is seven times higher than in Japan, which consumes the least. The country comparison figure on formal wear shows how important the laundering frequency is for total impacts. Even though the Japanese use more of the most energy-demanding form of cleaning, dry cleaning, their cleaning frequency is much reduced, thus giving a much smaller impact per wear. They also have an energy advantage in laundering, since most laundry is washed in non-heated water and clothing is seldom tumble dried.

Woollen formal wear has the lowest energy use per wear event, mainly because it is worn more days between cleaning. This advantage remains even though a higher share is dry cleaned, which is more energy-intensive than washing by hand or in a washing machine. Regenerated cellulose fibres differ as they are more energy demanding, mainly due to more frequent laundering.

Figure 8 shows the energy use related to cleaning and drying t-shirts. There are large differences between fibres as well as between countries. Similar to suits, the frequency of washing contributes most to the differences. The use of woollen t-shirts consumes the least energy per wear, followed by the synthetic fibres, while t-shirts in cotton and regenerated cellulose have the largest energy use. The differences between countries are even greater than between fibres. Again, the United States stands out due to its high energy use, followed by the UK, Germany, China and finally Japan, where decidedly less energy is used.

Figure 9 shows the energy use for one wear of socks/stockings and, again, we see that differences between countries are greater than between fibres, and the US stands out as the country that uses the most energy to keep clothes clean.

Figure 10 gives a further calculation for $\mathrm{CO}_{2}$ emissions for one year of use of the three garment types. For this calculation, it is assumed that socks and t-shirts are worn every day, while formal wear is worn during workdays only, and thus excludes weekends, annual leave and public holidays based on country averages (see Appendix A Table A9 for the number of days per country). Greenhouse gas 
(GHG) emissions are based on a country's electricity grid (see Table A8 in Appendix A). Differences in emissions are significant between the different fibres as well as countries. Emissions from the use of wool t-shirts are the lowest, with $4.08 \mathrm{~kg} \mathrm{CO}_{2}$, while cotton and regenerated cellulose t-shirts have almost double the amount of emissions. Cultural differences are even larger, as emissions per year are over four times more in the US than in Japan.

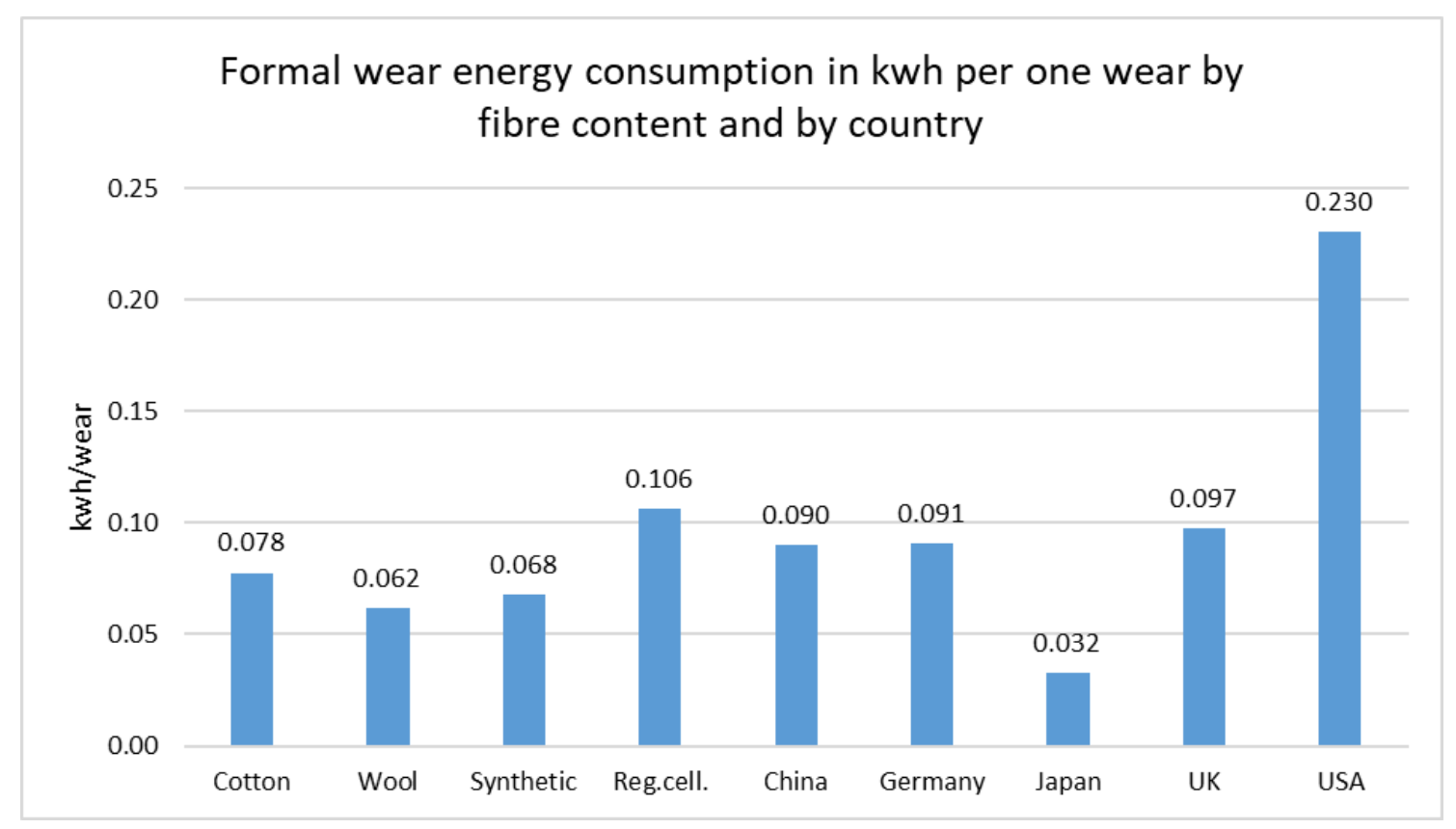

Figure 7. Energy use for one use of formal wear (suits).

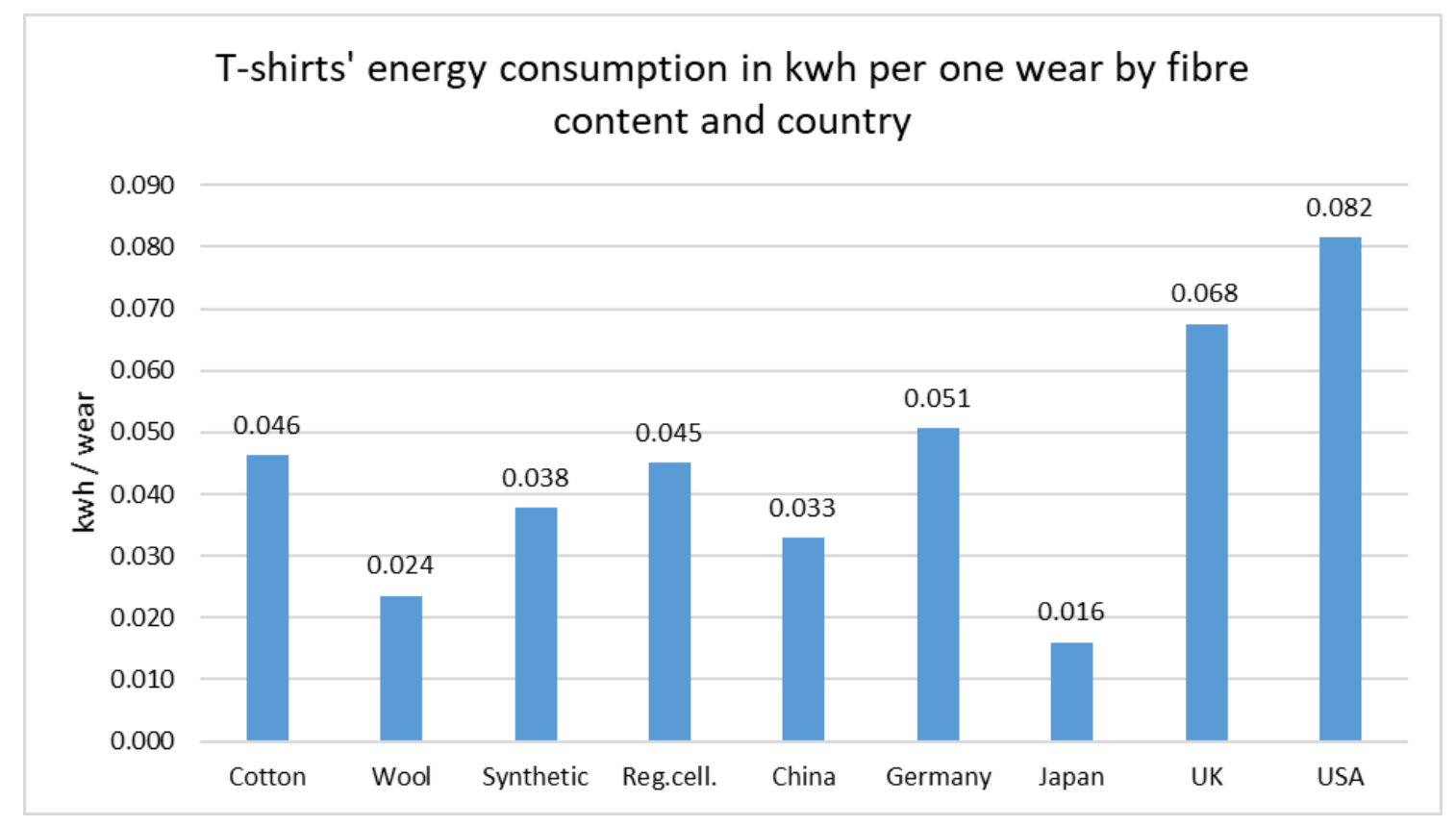

Figure 8. Energy use for one use of t-shirt/polo shirt/singlet.

$\mathrm{CO}_{2}$ emissions from using wool socks are about half compared to other fibres, mainly due to a reduced laundering frequency but also due to lesser use of a dryer. This estimate indicates that the use of wool socks instead of cotton or viscose socks would save $1.6-1.7 \mathrm{~kg} \mathrm{CO}_{2}$ per year. The difference in annual emissions to keep a pair of socks clean between the US and Japan is $4.3 \mathrm{kgCO}_{2} /$ year. 
The results give chiefly the same picture as energy use per wear, but the UK comes out better than in the previous comparison due to the smaller GHG emissions from electricity use when compared to China or Germany.

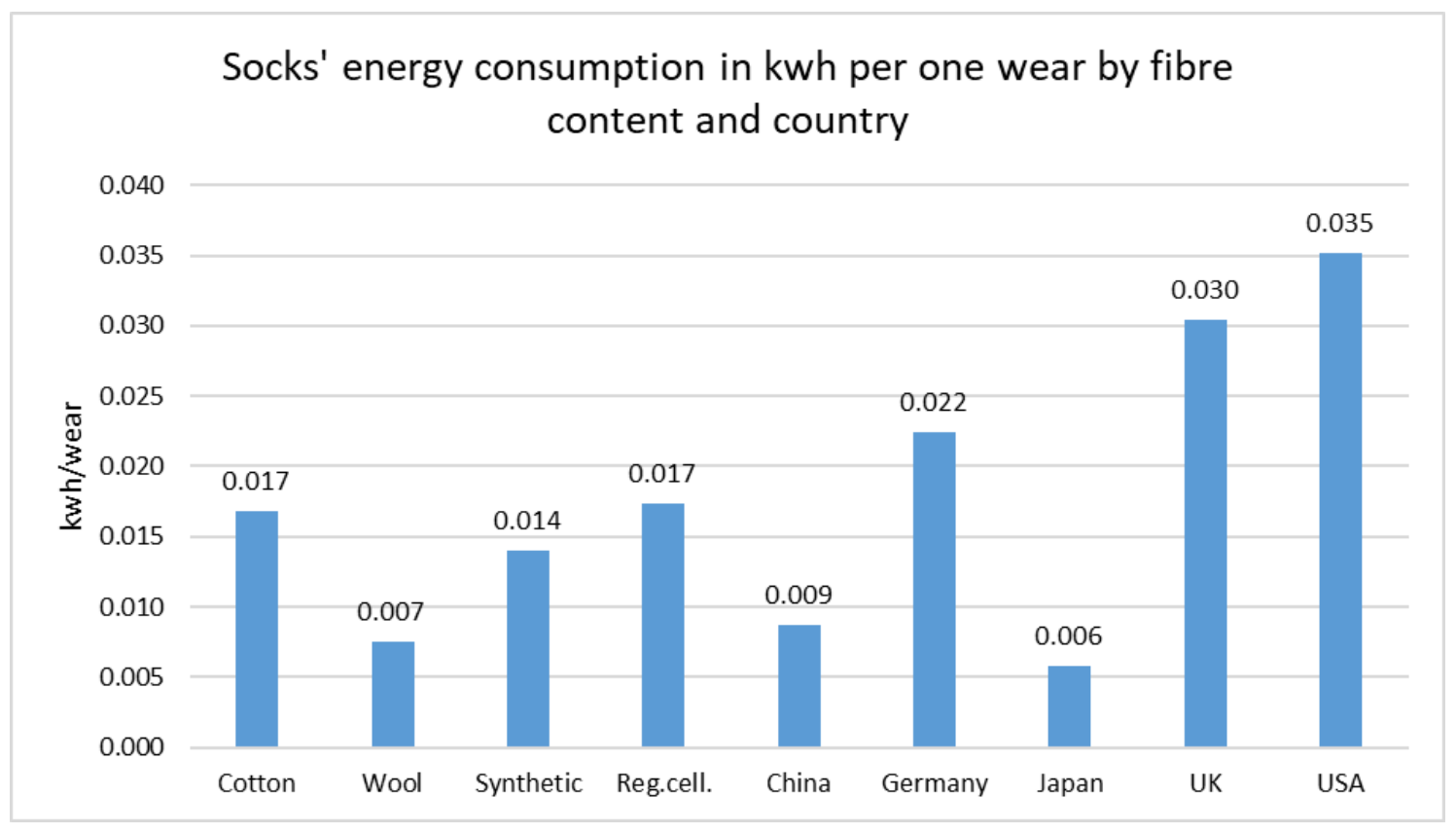

Figure 9. Energy use for one use of socks/stockings.

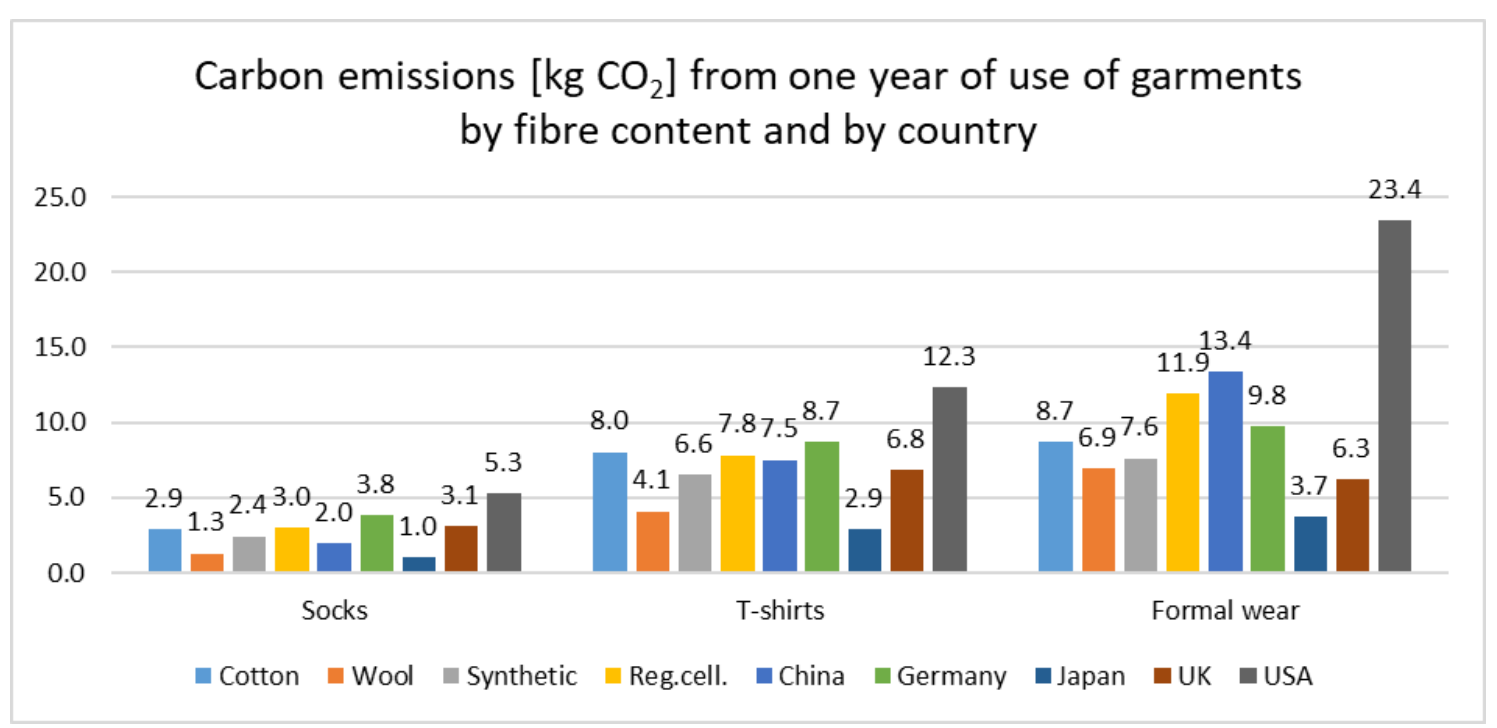

Figure 10. GHG emissions as for one year of use of garments by fibre content and by country.

\subsubsection{Water Use}

In addition to energy use, we calculated water use for one wear of each of the three garment types (Figure 11). The main differences are caused by cleaning frequency, whether products are dry cleaned with PERC, and whether condenser type tumble dryers are used. There are great variations between dry cleaning technologies. In general, a professional wet-cleaning process uses more water than the dry cleaning process, while the opposite applies for energy use [30,74-77]. Dry cleaning with PERC does not use water, but the related operations such as the cooling and cleaning of machines may have high consumption if the water is not reused, as in our assumption. 


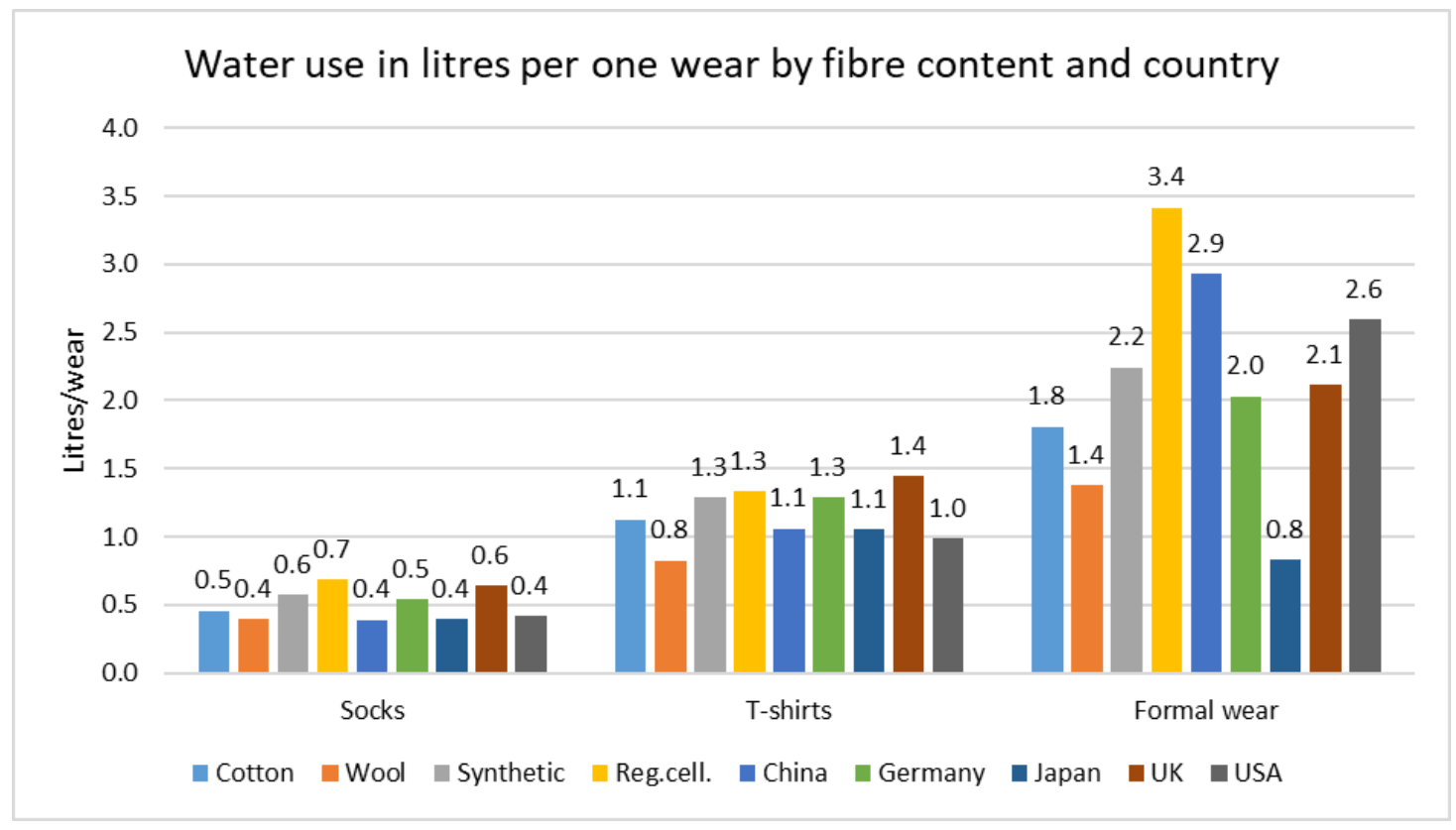

Figure 11. Water use for one use of the three garment groups (formal wear, t-shirt and socks) by fibre content and country.

Some of the tendencies in results are the same as for energy use, for example, that wool garments use the least water per wear. However, the order of consumption values for the five countries varies more. The most water is used for cleaning formal wear in China and in the US, while the UK comes higher in water use in the cleaning of socks and t-shirts. Differences in the cleaning of socks are, in general, minor as the cleaning methods do not include dry cleaning.

The water use in China and Japan might be less than estimated due to the potential reuse of grey water. Every third Chinese respondent agreed to the statement that they re-use the grey water that comes out of the washing machine, while $38 \%$ of Japanese respondents agreed that they reuse the grey water from showering in their washing machine. These two practices are much less common in other countries. This has not been taken into account in water use calculations, because we do not have any details on the figures, and the estimates would become very uncertain. However, in China, it is also common to use extra pre-washes in rinses, and these are not taken into account either due to a lack of data that are detailed enough.

\subsubsection{Limitations}

The research is not a complete life cycle study, as it excludes the production of textiles, washing machines and dryers. Additionally, the calculations do not take into account other environmental impacts caused by laundering, such as pollution-related to use of laundry chemicals and spread of microfibres. Concerning the laundry chemicals, it is likely that the differences between countries are mostly related to local infrastructure and the cleaning efficiency of the wastewater treatment plants, as well as regulations on what such laundry products are allowed to contain. Moreover, how the various dry cleaning solvents are handled will have a major impact on workers' health as well as environmental impacts.

Concerning microfibres, even though all textiles release them to some degree in laundering, the main difference in the environmental impacts is in their biodegradability. In this sense, synthetic fibres have the largest negative impact. Previous research has indicated that the type of washing machine, selected program, washing temperature and detergents also have an impact on how many fibres are released [22,23,78-80]. 
The survey and diary methods have also their limitations. It was not possible to register detailed information about garments in cases where they are made of blends, thus making the division between fibre categories more complicated. We have not included ironing or the use of fabric softeners in our calculations.

\section{Discussion}

Comparing our results to the previous literature, we find similarities but also significant differences, especially related to the assumptions about consumer behaviour. A study in the UK indicated that the cleaning of a cotton $\mathrm{t}$-shirt would require $0.722 \mathrm{kwh}$ while a viscose blouse would only use $0.077 \mathrm{kwh}$ per cleaning cycle [10]. Our estimate for the UK was $0.150 \mathrm{kwh} /$ wash cycle of t-shirts $(0.068 \mathrm{kwh}$ per wear), which shows that for the UK, the cleaning estimations made for the care of a viscose blouse are closer to current cleaning practices for $t$-shirts (lower laundering temperature and reduced use of clothes dryers). Additionally, differences between the two studies are likely caused by differences in system boundaries as well as improvements in the efficiencies of washing machines and driers since 2006 [81].

A life cycle inventory of a t-shirt used in Germany showed a fivefold difference between the most energy-intensive cleaning scenario with inefficient machines, a high temperature and the use of a clothes dryer, where GHG emissions were $198 \mathrm{~g} \mathrm{CO}_{2}$ per cleaning cycle, compared to the most energy-efficient cleaning method ( $40 \mathrm{~g} \mathrm{CO}_{2}$ per cleaning cycle) [82]. Our figure (52 $\mathrm{g} \mathrm{CO}_{2}$ per cleaning cycle) is closer to the lower estimate, even though our calculations include energy use for detergents, some dry cleaning, as well as the energy consumption for drying a share of the $t$-shirts in a heated room.

A study in Japan found that washing and drying an underwear shirt emitted between 24.3 and $69.4 \mathrm{~g} \mathrm{CO}_{2}$ per cleaning cycle and shirt, depending on the type of washer-dryer and shirt material [83]. The study aimed to look specifically into differences between dryers and the importance of materials for electricity consumption, and thus our emission result ( $16.6 \mathrm{~g} \mathrm{CO}_{2}$ per cleaning cycle) is closer to their lower estimate, which seems to be more realistic for current Japanese laundering practices. At the same time, the higher Japanese estimate is close to our results for emissions in the USA $\left(67.4 \mathrm{~g} \mathrm{CO}_{2}\right.$ per wash), where the use of clothes dryers dominates.

Moazzema et al. [7] compared the environmental impacts of cotton, wool and polyester apparel and showed that energy use was the main contributor to environmental impacts. For cotton and polyester apparel, the main contributor to climate change was the consumer use stage, whereas the wool apparel production process had a larger impact. Our study does not include the production phase, and demonstrates that woollen garments consume less energy than other materials during use.

The many similarities with previous research support our results, especially when comparable use phase assumptions are made. At the same time, the significant differences demonstrate the need for detailed use phase data to enable a comparison of different products using an environmental footprint methodology. We also see that the knowledge base needs to be updated regularly to reflect advances in technologies and changes in consumer practices over time.

\section{Conclusions}

We have shown that garments made of different fibres have different environmental impacts in the use phase. Laundering frequency is the most influential factor for differences in the environmental impacts per wear between garment types. Woollen garments have the lowest water and energy use per wear, as well as related GHG emissions, mainly due to the reduced laundering frequency. Larger items such as suits have a bigger impact, but not proportionally based on garment weight since they are cleaned less frequently than next-to-skin items such as socks and t-shirts. Garment type, particularly its proximity to the skin, is the dominant factor influencing washing frequency. The drying method contributes significantly to the variance in energy use between garments made of different fibres. Dry cleaning uses a lot of energy, and therefore garment types that are seldom dry cleaned, such as socks and $\mathrm{t}$-shirts, have the largest benefits. 
The odour intensity of various materials alone does not explain the differences in washing frequency. In some cases, synthetic clothes are washed less frequently than the cotton garments, even though research indicates that synthetic garments are the most odour intensive [49,50]. This could be because the types of garments are different and thus used for different occasions but may also be related to other factors that cause frequent washing of cotton, such as the design of garments and structure of the fabrics.

We see that the five countries have different practices and thus also different improvement potential. Consumption values in the US are usually the highest, mainly due to extensive use of clothes dryers and less efficient washing machines. Japan has the lowest energy use, mainly due to the use of unheated water in laundering, and line drying of clothing instead of using clothes dryers.

\subsection{Implications}

Our results have implications for environmental assessments, especially for improving the modelling of the use phase and functional unit in LCAs, and work such as the PEFCRs initiative in the EU, by providing quantified information on the use phase with significant differences between fibres, garment types and countries.

They can also be used in identifying the most feasible and efficient environmental strategies. Adopting best practice garment care in countries like the US, where reducing the use of clothes dryers and replacing washing machines with newer Energy Star-labelled front-loading types of machines would achieve great benefits. In Japan and China, further improvements could be made by reducing dry cleaning. Chinese consumers could also reduce pre-washing and extra rinsing and increase the use of full washing machine loads. European countries such as the UK and Germany could reduce washing temperatures to lower levels, closer to the three other countries in the study.

Considerable improvements in the efficiency of washing machines have been achieved in recent decades $[84,85]$. Our work shows that there is now more to be gained through changing consumers' cleaning practices, especially related to laundering frequency, which is the most important indicator of energy consumption during the use phase. This can be done through the transition to fibres that are washed less frequently such as wool and changing laundry habits towards best practice for the fibre. This is followed by whether clothing is dried in a clothes dryer, the washing temperature and the type of washing machine, and how clothing is dry cleaned. The large differences observed between countries in the knowledge and practices of dry cleaning indicate significant potential for improvement. Substituting solvent-based dry cleaning with professional wet-cleaning or some other suitable cleaning method at home would be beneficial [76].

Our research contributes more detailed information on the laundering practices of different garment types, covering a larger geographical area than any previous research. This variation in the practices of keeping clothing clean should be taken into account in environmental assessments of clothing and used when forming policies for sustainable clothing consumption. Our study also indicates the benefits of focusing future environmental work on habits and culture and not only on improving technologies in order to achieve greater environmental improvements.

\subsection{Future Research Directions}

We suggest that future research should focus on the following:

- Regions such as South America and Africa, as well as other types of textiles such as bed linen and sportswear.

- The causes of the big differences in the cleaning methods and frequencies-here, more local qualitative studies will contribute.

- The construction of garments to reduce the environmental impact of cleaning.

- Accounting for microplastics and the potential ecotoxicity of detergents in life cycle assessments.

- How to implement the best practices in laundering as an environmental strategy 
Author Contributions: Conceptualization, I.G.K. and K.L.; formal analysis, K.L.; investigation, K.L.; methodology, I.G.K. and K.L.; writing - original draft, I.G.K. and K.L.; writing-review and editing, I.G.K., K.L., R.K. and S.W. All authors have read and agreed to the published version of the manuscript.

Funding: This work was supported by Australian wool growers and the Australian government through Australian Wool Innovation Limited (AWI), contract number 4500012208, and the Research Council of Norway, project number 303080 .

Acknowledgments: We would like to thank Nielsen AG for conducting the survey and diary study, and Angus Ireland from AWI for commenting on the article draft.

Conflicts of Interest: The founding sponsor AWI financed and approved the publication, but did not influence the representation or interpretation of the reported research results. The Norwegian Research Council had no role in the design of the study; in the collection, analyses, or interpretation of data; in the writing of the manuscript, or in the decision to publish the results.

\section{Appendix A}

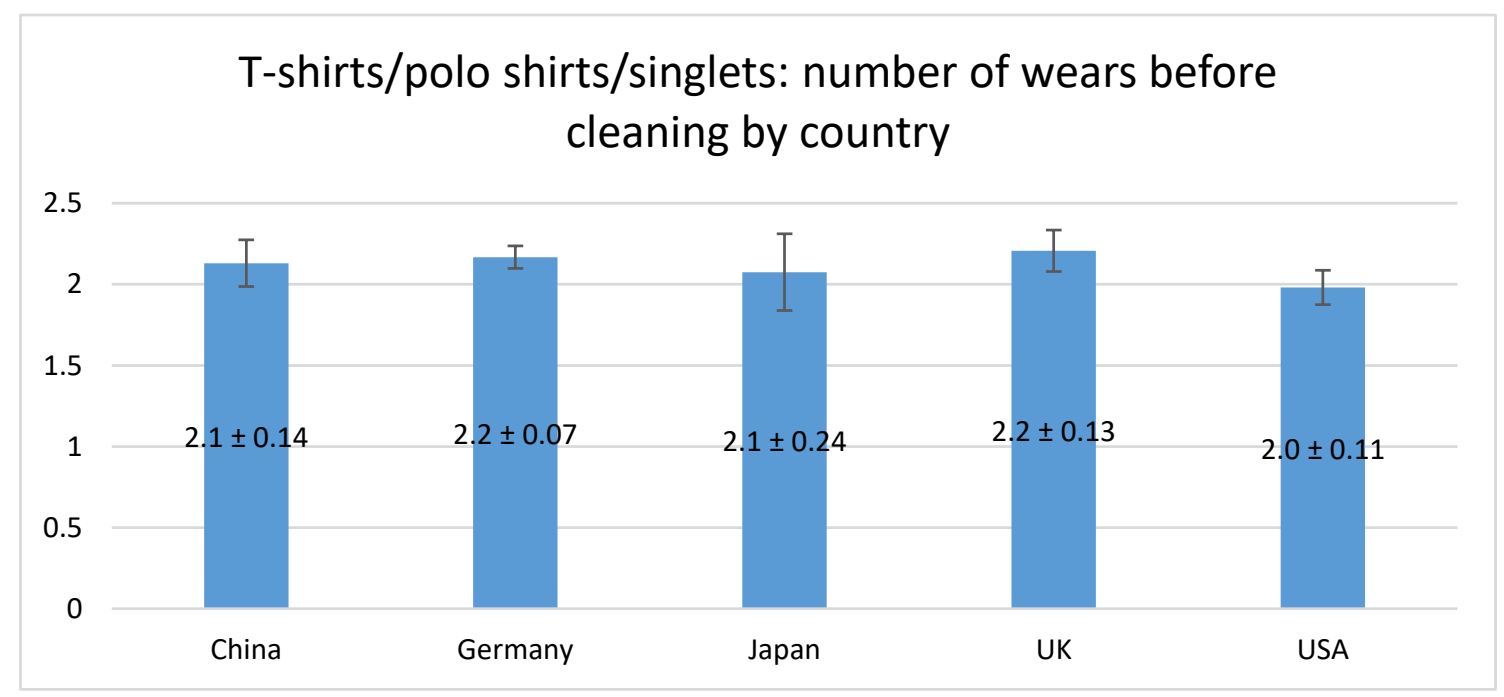

Figure A1. Number of days t-shirts/polo shirts/singlets are worn between cleaning by country. Mean with $95 \%$ confidence intervals. Wardrobe survey data, $\mathrm{N}=8656$ garments. One-way ANOVA $\mathrm{F}(4,8651)=1.44, p=0.218$.

\section{Socks and stockings: number of wears before cleaning by country}

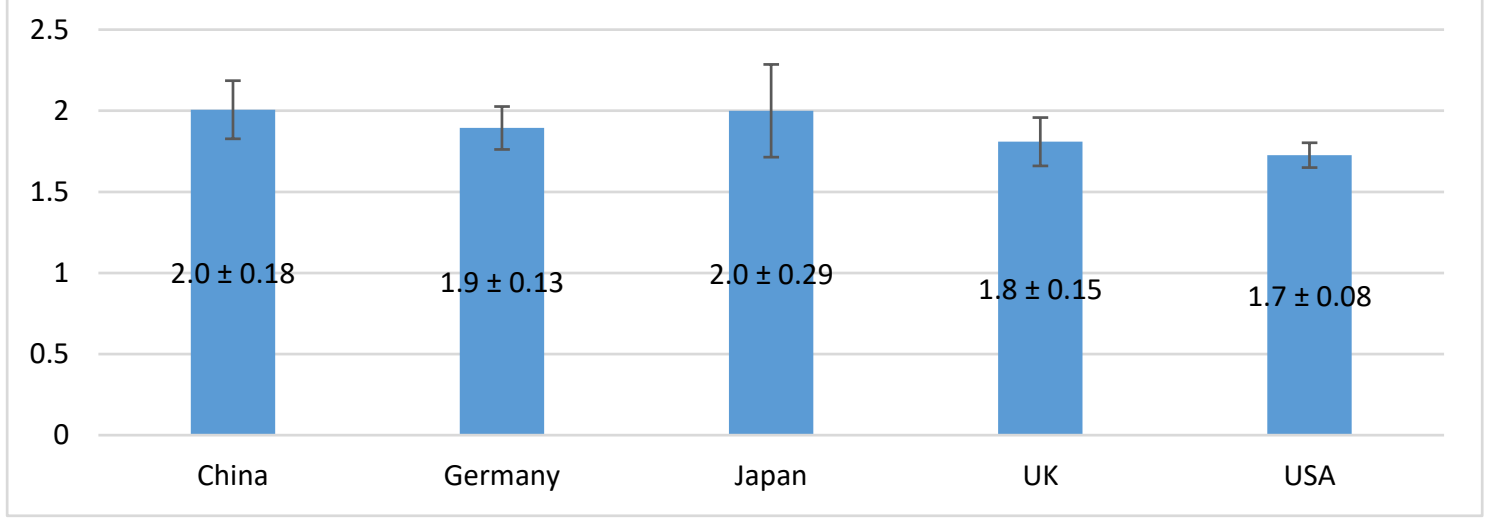

Figure A2. Number of days socks and stockings are worn between cleaning by country. Mean with $95 \%$ confidence intervals. (Wardrobe survey data, $\mathrm{N}=9015$ garments. One-way $\operatorname{ANOVA~F}(4,9010)=1.81$, $p=0.125$. 
Table A1. Detailed washing frequency results with mean and median values, standard deviation and number of garments in each category by fibre content and country.

\begin{tabular}{|c|c|c|c|c|c|c|}
\hline Garment Category & Fibre Content & Country & Mean & Median & Std. Deviation & $\mathbf{N}$ \\
\hline \multirow{30}{*}{$\begin{array}{l}\text { Formal wear (suits, } \\
\text { trousers and skirts) }\end{array}$} & \multirow{8}{*}{ Cotton and blends } & China & 3.6 & 3.0 & 4.5 & 777 \\
\hline & & Germany & 5.5 & 3.0 & 7.3 & 525 \\
\hline & & Japan & 9.7 & 5.0 & 13.9 & 565 \\
\hline & & UK & 5.5 & 3.0 & 10.2 & 500 \\
\hline & & USA & 3.0 & 2.0 & 3.8 & 658 \\
\hline & & Total & 5.3 & 3.0 & 8.8 & 3025 \\
\hline & & China & 4.1 & 3.0 & 3.0 & 269 \\
\hline & & Germany & 7.2 & 5.0 & 6.6 & 118 \\
\hline & \multirow{4}{*}{ Wool and blends } & Japan & 9.2 & 5.0 & 12.0 & 486 \\
\hline & & UK & 9.2 & 4.0 & 14.5 & 139 \\
\hline & & USA & 5.0 & 3.0 & 5.7 & 169 \\
\hline & & Total & 7.2 & 4.0 & 10.0 & 1181 \\
\hline & \multirow{6}{*}{ Synthetics } & China & 3.5 & 2.0 & 5.5 & 265 \\
\hline & & Germany & 4.5 & 3.0 & 3.4 & 79 \\
\hline & & Japan & 6.6 & 4.0 & 8.7 & 289 \\
\hline & & UK & 5.7 & 3.0 & 9.9 & 130 \\
\hline & & USA & 2.5 & 2.0 & 2.8 & 116 \\
\hline & & Total & 4.8 & 3.0 & 7.2 & 879 \\
\hline & \multirow{6}{*}{ Regenerated cellulose } & China & 3.1 & 2.0 & 2.6 & 107 \\
\hline & & Germany & 3.8 & 3.0 & 2.0 & 32 \\
\hline & & Japan & 4.1 & 4.5 & 2.8 & 16 \\
\hline & & UK & 3.3 & 1.0 & 8.6 & 32 \\
\hline & & USA & 3.5 & 2.0 & 3.4 & 23 \\
\hline & & Total & 3.3 & 2.0 & 4.1 & 210 \\
\hline & \multirow{6}{*}{ Total } & China & 3.6 & 3.0 & 4.4 & 1418 \\
\hline & & Germany & 5.6 & 3.0 & 6.8 & 754 \\
\hline & & Japan & 8.8 & 5.0 & 12.2 & 1356 \\
\hline & & UK & 6.1 & 3.0 & 11.1 & 801 \\
\hline & & USA & 3.3 & 2.0 & 4.1 & 966 \\
\hline & & Total & 5.5 & 3.0 & 8.7 & 5295 \\
\hline \multirow{24}{*}{$\begin{array}{c}\text { T-shirts/polo } \\
\text { shirts/singlets/tanks }\end{array}$} & \multirow{7}{*}{ Cotton and blends } & China & 2.0 & 1.0 & 2.6 & 924 \\
\hline & & Germany & 2.1 & 2.0 & 1.4 & 1727 \\
\hline & & Japan & 1.9 & 1.0 & 5.5 & 1398 \\
\hline & & UK & 2.1 & 1.0 & 2.6 & 1232 \\
\hline & & USA & 1.9 & 1.0 & 2.2 & 1645 \\
\hline & & Total & 2.0 & 1.0 & 3.1 & 6926 \\
\hline & & China & 3.3 & 3.0 & 3.4 & 129 \\
\hline & \multirow{6}{*}{ Wool and blends } & Germany & 3.2 & 3.0 & 2.7 & 148 \\
\hline & & Japan & 3.5 & 2.0 & 5.8 & 95 \\
\hline & & UK & 3.2 & 3.0 & 2.2 & 67 \\
\hline & & USA & 4.4 & 3.0 & 4.4 & 74 \\
\hline & & Total & 3.5 & 3.0 & 3.9 & 513 \\
\hline & & China & 2.0 & 1.0 & 2.4 & 121 \\
\hline & \multirow{5}{*}{ Synthetics } & Germany & 2.2 & 2.0 & 2.2 & 149 \\
\hline & & Japan & 2.0 & 1.0 & 2.2 & 265 \\
\hline & & UK & 2.7 & 2.0 & 2.3 & 107 \\
\hline & & USA & 1.9 & 1.0 & 1.8 & 123 \\
\hline & & Total & 2.1 & 1.0 & 2.2 & 765 \\
\hline & \multirow{6}{*}{ Regenerated cellulose } & China & 1.8 & 1.0 & 1.2 & 65 \\
\hline & & Germany & 1.9 & 2.0 & 1.2 & 55 \\
\hline & & Japan & 3.0 & 1.0 & 4.3 & 14 \\
\hline & & UK & 1.7 & 2.0 & 0.7 & 19 \\
\hline & & USA & 1.7 & 1.0 & 1.1 & 27 \\
\hline & & Total & 1.9 & 1.0 & 1.6 & 180 \\
\hline
\end{tabular}


Table A1. Cont.

\begin{tabular}{|c|c|c|c|c|c|c|}
\hline Garment Category & Fibre Content & Country & Mean & Median & Std. Deviation & $\mathbf{N}$ \\
\hline \multirow{6}{*}{$\begin{array}{c}\text { T-shirts/polo } \\
\text { shirts/singlets/tanks }\end{array}$} & \multirow{6}{*}{ Total } & China & 2.1 & 1.0 & 2.6 & 1239 \\
\hline & & Germany & 2.2 & 2.0 & 1.7 & 2079 \\
\hline & & Japan & 2.0 & 1.0 & 5.1 & 1772 \\
\hline & & UK & 2.2 & 2.0 & 2.5 & 1425 \\
\hline & & USA & 2.0 & 1.0 & 2.4 & 1869 \\
\hline & & Total & 2.1 & 1.0 & 3.1 & 8384 \\
\hline \multirow{30}{*}{ Pairs of socks/stockings } & \multirow{8}{*}{ Cotton and blends } & China & 1.9 & 1.0 & 3.9 & 1318 \\
\hline & & Germany & 1.6 & 1.0 & 2.0 & 1519 \\
\hline & & Japan & 2.0 & 1.0 & 6.6 & 1057 \\
\hline & & UK & 1.5 & 1.0 & 2.1 & 1201 \\
\hline & & USA & 1.6 & 1.0 & 1.3 & 1419 \\
\hline & & Total & 1.7 & 1.0 & 3.5 & 6514 \\
\hline & & China & 3.1 & 2.0 & 4.7 & 214 \\
\hline & & Germany & 3.8 & 2.0 & 5.4 & 197 \\
\hline & \multirow{4}{*}{ Wool and blends } & Japan & 3.7 & 1.0 & 8.8 & 168 \\
\hline & & UK & 3.2 & 2.0 & 5.8 & 229 \\
\hline & & USA & 3.0 & 2.0 & 3.3 & 172 \\
\hline & & Total & 3.4 & 2.0 & 5.8 & 980 \\
\hline & \multirow{6}{*}{ Synthetics } & China & 1.6 & 1.0 & 2.4 & 141 \\
\hline & & Germany & 2.3 & 1.0 & 5.6 & 159 \\
\hline & & Japan & 1.4 & 1.0 & 3.7 & 371 \\
\hline & & UK & 1.9 & 1.0 & 2.2 & 171 \\
\hline & & USA & 1.5 & 1.0 & 1.1 & 136 \\
\hline & & Total & 1.7 & 1.0 & 3.5 & 978 \\
\hline & \multirow{6}{*}{ Regenerated cellulose } & China & 1.3 & 1.0 & 0.7 & 56 \\
\hline & & Germany & 1.9 & 1.0 & 1.6 & 21 \\
\hline & & Japan & 1.4 & 1.0 & 0.9 & 14 \\
\hline & & UK & 1.1 & 1.0 & 0.3 & 14 \\
\hline & & USA & 1.8 & 1.5 & 1.2 & 6 \\
\hline & & Total & 1.4 & 1.0 & 1.0 & 111 \\
\hline & \multirow{6}{*}{ Total } & China & 2.0 & 1.0 & 3.9 & 1729 \\
\hline & & Germany & 1.9 & 1.0 & 3.0 & 1896 \\
\hline & & Japan & 2.1 & 1.0 & 6.3 & 1610 \\
\hline & & UK & 1.8 & 1.0 & 3.0 & 1615 \\
\hline & & USA & 1.7 & 1.0 & 1.7 & 1733 \\
\hline & & Total & 1.9 & 1.0 & 3.9 & 8583 \\
\hline
\end{tabular}

Table A2. Sources for estimation of garment weight.

\begin{tabular}{cccc}
\hline & Web Sources $^{\mathbf{1}}$ & $\begin{array}{c}\text { Clothing Collected in } \\
\text { Textile Waste Project [86] }\end{array}$ & Average Used in Analysis \\
\hline Formal wear & 1.163 & 0.923 & 1.0 \\
T-shirts & 0.218 & 0.186 & 0.2 \\
Socks/stockings & 0.081 & 0.058 & 0.07 \\
\hline
\end{tabular}

${ }^{1}$ https://www.parcl.com/education/forwarders/docs/parcl-approximate-weight-of-goods.pdf, https://www.wayfaire rtravel.com/inspiration/holiday-packing-calculator/, https://www.norrona.com/en-GB/products/falketind/falketindmid-weight-merino-socks/, https://www.meetsocks.com/ship-socks-china.html.

Table A3. Washing machine and programme info. Source: consumption values of machines used by diary participants, where available. Exceptions are the US, where values are acquired from Energy star [38], and Japan, where we used data for cold wash based on information from European washing machines validated by data from measurements in Japan [83].

\begin{tabular}{cccc}
\hline Category & Program & Energy kwh/kg Laundry & Water litres/kg Laundry \\
\hline Cotton & Cotton $30^{\circ} \mathrm{C}$ & 0.092 & 10.1 \\
Wool & Wool $30^{\circ} \mathrm{C}$ & 0.090 & 19.6 \\
\hline
\end{tabular}


Table A3. Cont.

\begin{tabular}{cccc}
\hline Category & Program & Energy $\mathbf{k w h} / \mathbf{k g}$ Laundry & Water litres/kg Laundry \\
\hline Synth. & Mixed fabrics $30^{\circ} \mathrm{C}$ & 0.086 & 13.1 \\
Reg. cell. & Mixed fabrics $30{ }^{\circ} \mathrm{C}$ & 0.086 & 13.1 \\
China & Average eco-labelling of machines & 0.088 & 12.8 \\
Germany & Cotton $1 / 2$ load $40^{\circ} \mathrm{C}$ & 0.165 & 13.2 \\
Japan & Cotton $20{ }^{\circ} \mathrm{C}$ & 0.051 & 9.0 \\
UK & Cotton $1 / 2$ load $40{ }^{\circ} \mathrm{C}$ & 0.165 & 13.2 \\
US & Average with and without energy label & 0.183 & 9.8 \\
\hline
\end{tabular}

Table A4. Energy and water use in dry cleaning and professional wet cleaning. Source: [77].

\begin{tabular}{lc}
\hline \multicolumn{1}{c}{ Category } & Use Values \\
\hline Energy, PERC kwh/kg & 0.390 \\
Energy, wet cleaning kwh/kg & 0.175 \\
Water in PERC cleaning, litres/kg & 0.007 \\
Water in wet cleaning, litres/kg & 22.91 \\
\hline
\end{tabular}

Table A5. Energy and water use in drying. Source: Consumption values of a selection of dryers used by diary participants, and indoors energy use from [34].

\begin{tabular}{lc}
\hline \multicolumn{1}{c}{ Category } & Use Values \\
\hline Condenser type clothes dryer with water heat exchanger, litres/kg laundry & 10.75 \\
Condenser/combi dryer energy per cycle kwh/kg laundry & 1.112 \\
Vented dryer energy use, kwh/kg laundry & 0.64 \\
Energy use in line-drying, heated room kwh/kg laundry & 0.34 \\
\hline
\end{tabular}

Table A6. GHG emissions for the production of different types of detergents per wash cycle [25].

\begin{tabular}{cc}
\hline Type of Detergent & $\begin{array}{c}\text { Emissions } \\
\text { [g CO }\end{array}$-eq/Wash Cycle] \\
\hline Tablets & 170 \\
Powder & 84 \\
Liquid & 90 \\
Capsule & 110 \\
\hline
\end{tabular}

Table A7. Detergent types used in machine and hand wash based on diary data, and related GHG emissions.

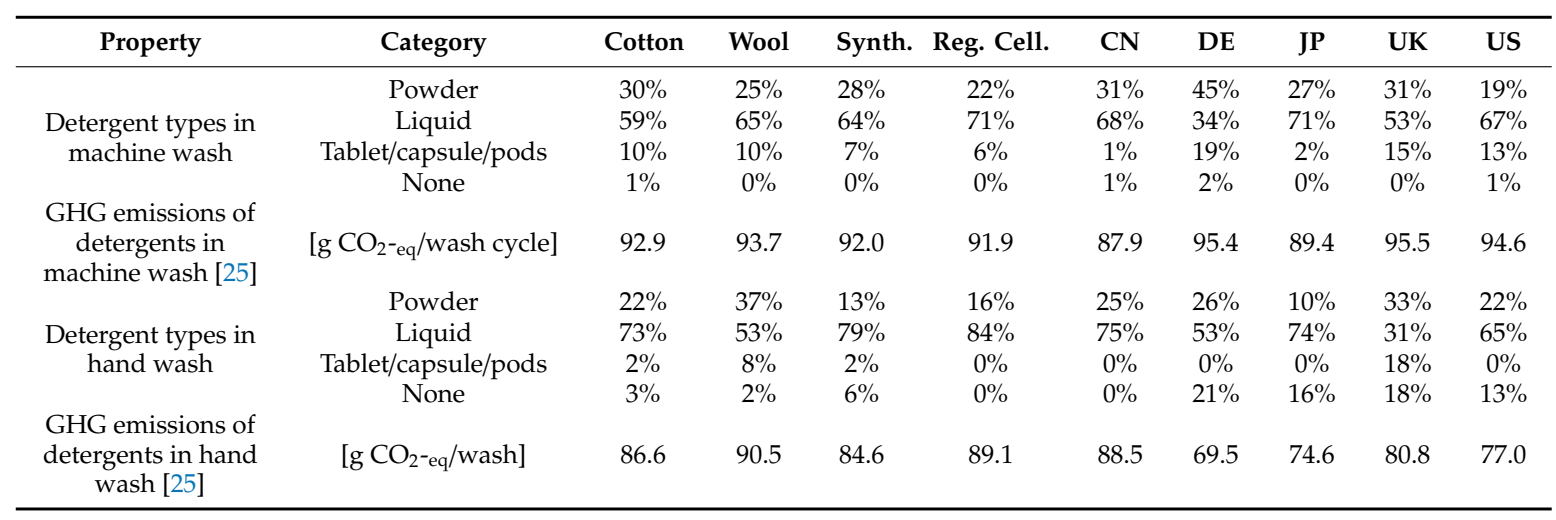


Table A8. $\mathrm{CO}_{2}$ emissions of grid electricity by country and global average $\left[\mathrm{gCO}_{2} / \mathrm{kWh}\right][87-89]$.

\begin{tabular}{cccc}
\hline Country & $\mathbf{g C O}_{\mathbf{2}} / \mathbf{k W h}$ & Year & Source \\
\hline China & 623.6 & 2017 & {$[88]$} \\
Germany & 469 & 2018 & {$[88]$} \\
Japan & 491.6 & 2017 & {$[88]$} \\
UK & 277.3 & 2019 & {$[88]$} \\
US & 413.2 & 2017 & {$[87]$} \\
Global average & 475 & 2018 & {$[89]$} \\
\hline
\end{tabular}

Table A9. Number of workdays per year used for calculating yearly use of formal wear. The estimation takes into account public holidays and annual leave (https://en.wikipedia.org/wiki/List_of_minimum_ annual_leave_by_country).

\begin{tabular}{cc}
\hline Country & Number of Working Days Per Year \\
\hline China & 239 \\
Germany & 230 \\
Japan & 234 \\
UK & 232 \\
USA & 246 \\
Average of the five countries & 236 \\
\hline
\end{tabular}

\section{References}

1. Shove, E. Comfort, Cleanliness and Convenience: The Social Organization of Normality; Berg: Oxford, UK, 2003.

2. Klepp, I.G. Patched, louse-ridden, tattered: Clean and dirty clothes. Text. J. Cloth Cult. 2007, 5, $254-275$. [CrossRef]

3. Quantis. Measuring Fashion. Environmental Impact of the Global Apparel and Footwear Industries Study; Quantis: Lausanne, Switzerland, 2018.

4. Lehmann, M.; Arici, G.; Boger, S.; Martinez-Pardo, C.; Krueger, F.; Schneider, M.; Carrière-Pradal, B.; Schou, D. Pulse of the Fashion Industry-2019 Update; Global Fashion Agenda: Copenhagen, Denmark; Boston Consulting Group: Boston, MA, USA; Sustainable Apparel Coalition: San Francisco, CA, USA, 2019.

5. The Business of Fashion and McKinsey \& Company. The State of Fashion 2019; The Business of Fashion: New York, NY, USA; McKinsey \& Company: New York, NY, USA, 2019.

6. Wiedemann, S.G.; Biggs, L.; Nebel, B.; Bauch, K.; Laitala, K.; Klepp, I.G.; Swan, P.G.; Watson, K. Environmental impacts associated with the production, use, and end-of-life of a woollen garment. Int. J. Life Cycle Assess. 2020, 25, 1486-1499. [CrossRef]

7. Moazzem, S.; Daver, F.; Crossin, E.; Wang, L. Assessing environmental impact of textile supply chain using life cycle assessment methodology. J. Text. Inst. 2018, 109, 1574-1585. [CrossRef]

8. Muthu, S.S. Handbook of Life Cycle Assessment (LCA) of Textiles and Clothing; Woodhead Publishing and the Textile Insitute: Cambridge, UK, 2015.

9. Madsen, J.; Hartlin, B.; Perumalpillai, S.; Selby, S.; Aumônier, S. Mapping of Evidence on Sustainable Development Impacts That Occur in Life Cycles of Clothing: A Report to Defra; Environmental Resources Management Ltd: London, UK, 2007.

10. Allwood, J.M.; Laursen, S.E.; Malvido de Rodríquez, C.; Bocken, N.M.P. Well Dressed? The Present and Future Sustainability of Clothing and Textiles in the United Kingdom; University of Cambridge, Institute for Manufacturing: Cambridge, UK, 2006.

11. Pakula, C.; Stamminger, R. Electricity and water consumption for laundry washing by washing machine worldwide. Energy Effic. 2010, 3, 365-382. [CrossRef]

12. Bain, J.; Beton, A.; Schultze, A.; Mudgal, S.; Dowling, M.; Holdway, R.; Owens, J. Reducing the Environmental Impact of Clothes Cleaning: A Research Report completed for Defra; BIO Intelligence Service in Collaboration with Giraffe and Intertek: London, UK, 2009.

13. IEA. Global Energy \& CO2 Status Report. The Latest Trends in Energy and Emissions in 2018; The International Energy Agency: Paris, France, 2019. 
14. Carbon Trust. International Carbon Flows_Clothing (CTC793); Carbon Trust: London, UK, 2011; p. 17.

15. EPA. Greenhouse Gas Equivalencies Calculator. Available online: https://www.epa.gov/energy/greenhousegas-equivalencies-calculator (accessed on 25 June 2020).

16. Gooijer, H.; Stamminger, R. Water and Energy Consumption in Domestic Laundering Worldwide-A Review. Tenside Surfactants Deterg. 2016, 53, 402-409. [CrossRef]

17. Giagnorio, M.; Amelio, A.; Grüttner, H.; Tiraferri, A. Environmental impacts of detergents and benefits of their recovery in the laundering industry. J. Clean. Prod. 2017, 154, 593-601. [CrossRef]

18. Golsteijn, L.; Menkveld, R.; King, H.; Schneider, C.; Schowanek, D.; Nissen, S. A compilation of life cycle studies for six household detergent product categories in Europe: The basis for product-specific A.I.S.E. Charter Advanced Sustainability Profiles. Environ. Sci. Eur. 2015, 27, 23. [CrossRef]

19. Saouter, E.; van Hoof, G.; Feijtel, T.C.J.; Owens, J.W. The effect of compact formulations on the environmental profile of northern European granular laundry detergents-Part II: Life cycle assessment. Int. J. Life Cycle Assess. 2002, 7, 27-38. [CrossRef]

20. Saouter, E.; van Hoof, G.; Pittinger, C.A.; Feijtel, T.C.J. The effect of compact formulations on the environmental profile of Northern European granular laundry detergents-Part I: Environmental Risk Assessment. Int. J. Life Cycle Assess. 2001, 6, 363-372. [CrossRef]

21. Greenpeace. Dirty Laundry: Reloaded; Greenpeace: Amsterdam, the Netherlands, 2012; p. 48.

22. Henry, B.; Laitala, K.; Klepp, I.G. Microfibres from apparel and home textiles: Prospects for including microplastics in environmental sustainability assessment. Sci. Total Environ. 2019, 652, 483-494. [CrossRef]

23. Schöpel, B.; Stamminger, R. A Comprehensive Literature Study on Microfibres from Washing Machines. Tenside Surfactants Deterg. 2019, 56, 94-104. [CrossRef]

24. Yasin, S.; Behary, N.; Rovero, G.; Kumar, V. Statistical analysis of use-phase energy consumption of textile products. Int. J. Life Cycle Assess. 2016. [CrossRef]

25. Shahmohammadi, S.; Steinmann, Z.; Clavreul, J.; Hendrickx, H.; King, H.; Huijbregts, M.A.J. Quantifying drivers of variability in life cycle greenhouse gas emissions of consumer products-A case study on laundry washing in Europe. Int. J. Life Cycle Assess. 2018, 23, 1940-1949. [CrossRef]

26. Union of Concerned Scientists. Environmental Impacts of Renewable Energy Technologies. Available online: https://www.ucsusa.org/resources/environmental-impacts-renewable-energy-technologies (accessed on 21 October 2019).

27. Laitala, K.; Klepp, I.G.; Henry, B. Does Use Matter? Comparison of Environmental Impacts of Clothing Based on Fiber Type. Sustainability 2018, 10, 2524. [CrossRef]

28. Laitala, K.; Boks, C.; Klepp, I.G. Potential for environmental improvements in laundering. Int. J. Consum. Stud. 2011, 35, 254-264. [CrossRef]

29. Laitala, K.; Klepp, I.G.; Henry, B. Global laundering practices. Alternatives to machine washing. HEPC Today Househ. Pers. Care Today 2017, 12, 10-16.

30. Sinsheimer, P.; Grout, C.; Namkoong, A.; Gottlieb, R.; Latif, A. The viability of professional wet cleaning as a pollution prevention alternative to perchloroethylene dry cleaning. J. Air Waste Manag. Assoc. 2007, 57, 172-178. [CrossRef]

31. Kim, J.; Park, Y.; Yun, C.; Park, C.H. Comparison of environmental and economic impacts caused by the washing machine operation of various regions. Energy Effic. 2015, 8, 905-918. [CrossRef]

32. Onasch, J. A feasibility and cost comparison of perchloroethylene dry cleaning to professional wet cleaning: Case study of Silver Hanger Cleaners, Bellingham, Massachusetts. J. Clean. Prod. 2011, 19, 477-482. [CrossRef]

33. TURI. Assessment of Alternatives to Perchloroethylene for the Dry Cleaning Industry; The Toxics Use Reduction Institute (TURI) at the University of Massachusetts Lowell: Lowell, MA, USA, 2012; p. 64.

34. Schmitz, A.; Stamminger, R. Usage behaviour and related energy consumption of European consumers for washing and drying. Energy Effic. 2014, 7, 937-954. [CrossRef]

35. Zimmermann, J.P.; Evans, M.; Griggs, J.; King, N.; Harding, L.; Roberts, P.; Evans, C. Household Electricity Survey-A Study of Domestic Electrical Product Usage; Intertek: Milton Keynes, UK, 2012; p. 600.

36. European Commission. Directive 2009/125/EC of the European Parliament and of the Council of 21 October 2009 Establishing a Framework for the Setting of Ecodesign Requirements for Energy-Related Products; European Parliament and the Council of the European Union: Brussels, Belgium, 2009. 
37. European Commission. Regulation (EU) 2017/1369 of the European Parliament and of the Council of 4 July 2017 Setting a Framework for Energy Labelling and Repealing Directive 2010/30/EU; European Parliament and the Council of the European Union: Brussels, Belgium, 2017.

38. Energy Star. ENERGY STAR Program Requirements Product Specification for Clothes Washers. Eligibility Criteria Version 8.0; U.S. Environmental Protection Agency: Washington, DC, USA; U.S. Department of Energy: Washington, DC, USA, 2018.

39. European Commission. Regulation (EC) No 1907/2006 of the European Parliament and of the Council of 18 December 2006 Concerning the Registration, Evaluation, Authorisation and Restriction of Chemicals (REACH), Establishing a European Chemicals Agency, Amending Directive 1999/45/EC and Repealing Council Regulation (EEC) No 793/93 and Commission Regulation (EC) No 1488/94 as well as Council Directive 76/769/EEC and Commission Directives 91/155/EEC, 93/67/EEC, 93/105/EC and 2000/21/EC; European Parliament and the Council of the European Union: Brussels, Belgium, 2006.

40. Frank, R. Lautenberg Chemical Safety for the 21st Century Act. In H.R.2576; US Environmental Protection Agency: Washington, DC, USA, 2016.

41. European Commission. Regulation (EC) No 66/2010 of the European Parliament and of the Council of 25 November 2009 on the EU Ecolabel; European Parliament and the Council of the European Union: Brussels, Belgium, 2010.

42. Spencer, J.; Lilley, D.; Porter, S. The opportunities that different cultural contexts create for sustainable design: A laundry care example. J. Clean. Prod. 2015, 107, 279-290. [CrossRef]

43. Spencer, J.; Lilley, D.; Porter, S. The implications of cultural differences in laundry behaviours for design for sustainable behaviour: A case study between the UK, India and Brazil. Int. J. Sustain. Eng. 2015, 8, 196-205. [CrossRef]

44. Laitala, K.; Klepp, I.G.; Boks, C. Changing laundry habits in Norway. Int. J. Consum. Stud. 2012, 36, $228-237$. [CrossRef]

45. Klepp, I.G.; Buck, M.; Laitala, K.; Kjeldsberg, M. What's the problem? Odor-control and the smell of sweat in sportswear. Fash. Pract. J. Des. Creat. Process. Fash. Ind. 2016, 8, 296-317. [CrossRef]

46. Laitala, K.; Klepp, I.G. Wool wash: Technical performance and consumer habits. Tenside Surfactants Deterg. 2016, 53, 458-469. [CrossRef]

47. Laitala, K.; Klepp, I.G.; Henry, B. Use phase of wool apparel: A literature review for improving LCA. In Proceedings of the Product Lifetimes and The Environment-PLATE 2017, Delft, The Netherlands, 9 November 2017; pp. 202-207.

48. McQueen, R.; Moran, L.J.; Cunningham, C.; Hooper, P.M.; Wakefield, K.A.M. The impact of odour on laundering behaviour: An exploratory study. Int. J. Fash. Des. Technol. Educ. 2019. [CrossRef]

49. Laing, R.M. Natural fibres in next-to-skin textiles: Current perspectives on human body odour. SN Appl. Sci. 2019, 1, 1329. [CrossRef]

50. McQueen, R.; Vaezafshar, S. Odor in textiles: A review of evaluation methods, fabric characteristics, and odor control technologies. Text. Res. J. 2019. [CrossRef]

51. Mukhtar Abdul-Bari, M.; McQueen, R.; Paulina de la Mata, A.; Batcheller, J.C.; Harynuk, J.J. Retention and release of odorants in cotton and polyester fabrics following multiple soil/wash procedures. Text. Res. J. 2020. [CrossRef]

52. Pugliese, S.; Jespersen, M.F.; Pernov, J.B.; Shenolikar, J.; Nygaard, J.; Nielsen, O.J.; Johnson, M.S. Chemical analysis and origin of the smell of line-dried laundry. Environ. Chem. 2020. [CrossRef]

53. Kaufmann, J.-C. Dirty Linen: Couples and Their Laundry; Middlesex University Press: London, UK, 1998.

54. Anderson, B. Laundry, energy and time: Insights from 20 years of time-use diary data in the United Kingdom. Energy Res. Soc. Sci. 2016, 22, 125-136. [CrossRef]

55. Jack, T. Nobody was dirty: Intervening in inconspicuous consumption of laundry routines. J. Consum. Cult. 2013, 13, 406-421. [CrossRef]

56. Alborzi, F.; Schmitz, A.; Stamminger, R. Long wash cycle duration as a potential for saving energy in laundry washing. Energy Effic. 2016. [CrossRef]

57. Ellmer, K.; Fuchs, M.; Bauer, U.; Schneider, T.; Thamsen, P.U.; Morgenthal, T.; Villwock, J.; Hanau, A. Research project Simulation Wäschepflege-Recommendations for improving resource efficiency in the laundry process in households in Germany. J. Clean. Prod. 2015. [CrossRef] 
58. Hustvedt, G.; Ahn, M.; Emmel, J. The adoption of sustainable laundry technologies by US consumers. Int. J. Consum. Stud. 2013, 37, 291-298. [CrossRef]

59. Hustvedt, G. Review of laundry energy efficiency studies conducted by the US Department of Energy. Int. J. Consum. Stud. 2011, 35, 228-236. [CrossRef]

60. Golden, J.S.; Subramanian, V.; Irizarri, G.M.A.U.; White, P.; Meier, F. Energy and carbon impact from residential laundry in the United States. J. Integr. Environ. Sci. 2010, 7, 53-73. [CrossRef]

61. Pakula, C.; Stamminger, R. Comparison of resources used for laundry washing worldwide. In Proceedings of the WFK 44th Int. Detergency Conference, Düsseldorf, Germany, 12-14 May 2009; pp. 68-73.

62. Paloviita, A.; Järvi, P. Environmental value chain management of laundry detergents in the use phase. Int. J. Consum. Stud. 2008, 32, 607-612. [CrossRef]

63. Fijan, S.; Fijan, R.; Sostar-Turk, S. Implementing sustainable laundering procedures for textiles in a commercial laundry and thus decreasing wastewater burden. J. Clean. Prod. 2008, 16, 1258-1263. [CrossRef]

64. European Commission. International Reference Life Cycle Data System (ILCD) Handbook—General Guide for Life Cycle Assessment_Detailed Guidance; European Commission, Joint Research Centre, Institute for Environment and Sustainability, Publications Office of the European Union: Luxemburg, 2010.

65. European Commission. Legislative Proposal on Substantiating Green Claims-Environmental Performance of Products \& Businesses - Substantiating Claims; DG Environment, Unit B1—Sustainable Production, Products and Consumption, European Commission: Brussels, Belgium, 2020.

66. Pesnel, S.; Payet, J. Product Environmental Footprint Category Rules (PEFCR)—T-Shirts; CYCLECO: Amberieu en Bugey, France, 2019; p. 130.

67. Van der Velden, N.M.; Patel, M.K.; Vogtländer, J.G. LCA benchmarking study on textiles made of cotton, polyester, nylon, acryl, or elastane. Int. J. Life Cycle Assess. 2014, 19, 331-356. [CrossRef]

68. Fletcher, K.; Klepp, I.G. Opening Up the Wardrobe: A Methods Book; Novus: Oslo, Norway, 2017; p. 195.

69. Klepp, I.G.; Bjerck, M. A methodological approach to the materiality of clothing: Wardrobe Studies. Int. J. Soc. Res. Methodol. 2014, 17, 373-386. [CrossRef]

70. Klepp, I.G.; Laitala, K.; Wiedemann, S. Clothing lifetimes: What should be measured and how. Sustainability 2020, 12, 6219. [CrossRef]

71. Sferrazza, F. How the Internet Is Empowering China's Older Generation. Available online: https: //www.sixthtone.com/news/1551/how-the-internet-is-empowering-chinas-older-generation (accessed on 19 April 2020).

72. NTP. Report on Carcinogens: Trichloroethylene, 14th ed.; US Department of Health and Human Services, Public Health Service: Research Triangle Park, NC, USA, 2016.

73. Roetzel, B. Gentleman: The Ultimate Companion to the Elegant Man; Ullmann Publishing: Potsdam, Germany, 2016.

74. Keoleian, G.A.; Blackler, C.E.; Denbow, R.; Polk, R. Comparative assessment of wet and dry garment cleaning: Part 1. Environmental and human health assessment. J. Clean. Prod. 1997, 5, 279-289. [CrossRef]

75. Keoleian, G.A.; Blackler, C.E.; Nemsick, K.; Levine, W. Comparative assessment of wet and dry garment cleaning: Part 2. Performance, economic and regulatory assessment. J. Clean. Prod. 1998, 6, 23-36. [CrossRef]

76. Troynikov, O.; Watson, C.; Jadhav, A.; Nawaz, N.; Kettlewell, R. Towards sustainable and safe apparel cleaning methods: A review. J. Environ. Manag. 2016, 182, 252-264. [CrossRef]

77. Blackler, C.; Denbow, R.; Levine, W.; Nemsick, K.; Polk, R. A Comparative Analysis of Perc Dry Cleaning and an Alternative Wet Cleaning Process; University of Michigan: Ann Arbor, MI, USA, 1995.

78. De Falco, F.; Di Pace, E.; Cocca, M.; Avella, M. The contribution of washing processes of synthetic clothes to microplastic pollution. Sci. Rep. 2019, 9, 6633. [CrossRef]

79. Kelly, M.R.; Lant, N.J.; Kurr, M.; Burgess, J.G. Importance of Water-Volume on the Release of Microplastic Fibers from Laundry. Environ. Sci. Technol. 2019, 53, 11735-11744. [CrossRef]

80. Zambrano, M.C.; Pawlak, J.J.; Daystar, J.; Ankeny, M.; Cheng, J.J.; Venditti, R.A. Microfibers generated from the laundering of cotton, rayon and polyester based fabrics and their aquatic biodegradation. Mar. Pollut. Bull. 2019, 142, 394-407. [CrossRef]

81. Boyano, A.; Espinosa, N.; Villanueva, A. Rescaling the energy label for washing machines: An opportunity to bring technology development and consumer behaviour closer together. Energy Effic. 2020, 13, 51-67. [CrossRef] 
82. Steinberger, J.; Friot, D.; Jolliet, O.; Erkman, S. A spatially explicit life cycle inventory of the global textile chain. Int. J. Life Cycle Assess. 2009, 14, 443-455. [CrossRef]

83. Yamaguchi, Y.; Seii, E.; Itagaki, M.; Nagayama, M. Evaluation of domestic washing in Japan using life cycle assessment (LCA). Int. J. Consum. Stud. 2011, 35, 243-253. [CrossRef]

84. European Commission. Commission Regulation (EU) No 1015/2010 of 10 November 2010 Implementing Directive 2009/125/EC of the European Parliament and of the Council with Regard to Ecodesign Requirements for Household Washing Machines. Off. J. Eur. Union 2010, 1015/2010, 21-30.

85. Stamminger, R.; Schmitz, A. Washing Machines in Europe-Detailed Assessment of Consumption and Performance. Tenside Surfactants Deterg. 2016, 53, 70-86. [CrossRef]

86. Laitala, K. Clothing Consumption-An Interdisciplinary Approach to Design for Environmental Improvement; Norwegian University of Science and Technology: Trondheim, Norway, 2014.

87. Transparency, C. Brown to Green: The G20 Transition to a Low-Carbon Economy; Climate Transparency, c/o Humboldt-Viadrina Governance Platform: Berlin, Germany, 2018.

88. Carbon Footprint. Country Specific Electricity Grid Greenhouse Gas Emission Factors; Carbon Footprint: Hampshire, UK, 2019.

89. IEA. Global Energy \& CO2 Status Report 2019; International Energy Agency: Paris, France, 2019.

(C) 2020 by the authors. Licensee MDPI, Basel, Switzerland. This article is an open access article distributed under the terms and conditions of the Creative Commons Attribution (CC BY) license (http://creativecommons.org/licenses/by/4.0/). 